\title{
Wave Propagation Methods for Determining Stiffness of Geomaterials
}

\author{
Auckpath Sawangsuriya \\ Additional information is available at the end of the chapter
}

http://dx.doi.org/10.5772/48562

\section{Introduction}

In many geoengineering design and analysis, the laboratory and field investigations are generally required to identify and classify geomaterials as well as to assess their engineering properties. One of the important engineering properties commonly used in geomechanical design and analysis is the stiffness of geomaterial. Such stiffness primarily describes the deformation characteristic of a geomaterial used to support engineered structures. Understanding the stiffness behaviour of geomaterials is therefore essential for improving design and analysis of structural behavior under varying loading and environmental conditions.

The importance of accurate stiffness measurements from small to large strains has gained increased recognition in both static and dynamic analyses over the past 20 years. In the static triaxial test, the local displacement transducer has been used to measure local axial strains (Goto et al. 1991). The resonant column and torsional shear devices have been widely used for many years to study cyclic and dynamic properties of geomaterials at strains ranging from $10^{-4}$ to $0.1 \%$ (Drnevich 1985, Saada 1988). The American Association of State Highway and Transportation Officials (AASHTO) has adopted the use of resilient modulus (MR) in pavement design, which is customarily used by the pavement community. The precise measurement of $M_{R}$ values of pavement materials is typically in the strain range from $10^{=2}$ to 0.1\% (Kim and Stokoe 1992).

Based on the typical variation of shear moduli with shear strain levels shown in Fig. 1 (after Atkinson and Sallförs 1991, Mair 1993, Ishihara 1996, Sawangsuriya et al. 2005), three strain ranges are defined: (1) very small strain, (2) small strain, and (3) large strain. The very small strain range corresponds to the range of strain less than the elastic threshold strain $\left(\gamma_{\mathrm{et}}\right)$, approximately between $10^{-3} \%$ and $10^{-2} \%$, depending on plasticity index $\left(\mathrm{I}_{\mathrm{p}}\right)$ for plastic soils (Vucetic and Dobry 1991) and on confining pressure $\left(\sigma_{\circ}\right)$ for non-plastic soils (Ishibashi and 
Zhang 1993). Within this very small strain region, the geomaterial exhibits linear-elastic behaviour and the shear modulus is independent of strain amplitude, approaching a nearly constant limiting value of the maximum shear modulus (Gmax). The small strain range starts from elastic threshold strain to $1 \%$ where the shear modulus is highly non-linear and straindependent. The large strain range corresponds to strain generally larger than $1 \%$. In the large strains, the geomaterial is approaching failure and the shear modulus is substantially decreased. In many geoengineering applications, e.g. foundations, retaining walls, tunnels, pavements etc., the stress-strain behavior of geomaterial is highly non-linear, resulting in shear modulus degradation with strain by orders of magnitude. The variation of shear moduli and other properties of geomaterial with respect to shear strain levels for different geotechnical applications as measured by in situ and laboratory tests are also shown in Fig. 1.

Estimation of stiffness has traditionally been made in a triaxial apparatus using precise displacement transducers or resonant column devices (Lo Presti et al. 2001). Although several methods become commercially available to determine the stiffness of geomaterials both in the laboratory and in the field, the wave propagation techniques are widely accepted for their rapid, non-destructive, and low-cost evaluation methods. By knowing the elastic wave velocities as measured with the wave-based techniques and total mass density of the media, the stiffness of the geomaterials can be determined. In particular, a shear or S-wave velocity is a keystone for calculating the shear modulus of geomaterial. Such S-wave measurement has been researched extensively using shear plates (e.g. Lawrence 1963, 1965), resonant column tests (e.g. Hardin and Drnevich 1972), and bender elements (e.g. Shirley 1978, Shirley and Hampton 1978). The use of the shear plates is limited due to their large size and their need for a high excitation voltage (Ismail et al. 2005) while complexities and high cost of test equipments are disadvantages of resonant column tests. In contrast, bender elements have gained reputation particularly in research on geoengineering because of their smaller size, and lower voltage required leading to easier operation. Such method also provides cost-effectiveness and realistic design parameter which in turn becomes most valuable tool for mechanistic-based design and analysis, long-term performance monitoring, quality control process during construction etc.

\section{Wave propagation methods for determining stiffness of geomaterials}

Wave propagation methods become popular techniques in the evaluation of stiffness of geomaterials and process monitoring both in the laboratory and in the field (Richart et al. 1970, Matthews et al. 2000, Santamarina et al. 2001, LoPresti et al. 2001). Table 1 summarizes the existing wave propagation methods used by the geoengineering community in the U.S. Some of them have already been approved by the American Society for Testing and Materials (ASTM). Wave propagation methods for determining stiffness of geomaterials have several advantages:

1. Most wave propagation methods are relatively simple, rapid, repeatable, and nondestructive. 


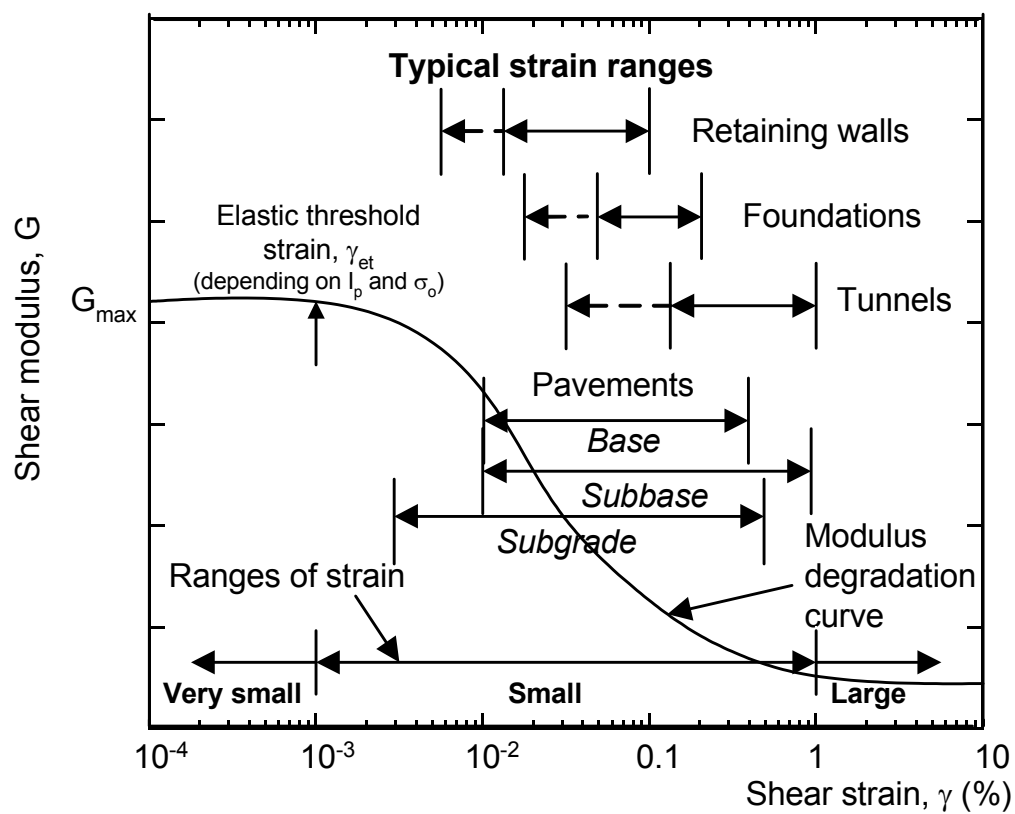

\begin{tabular}{|c|c|c|c|c|}
\hline \multicolumn{2}{|c|}{ Phenomena } & $\begin{array}{c}\text { Wave propagation, } \\
\text { vibration }\end{array}$ & $\begin{array}{l}\text { Crack, differential } \\
\text { settlement }\end{array}$ & $\begin{array}{l}\text { Slide, compaction, } \\
\text { liquefaction }\end{array}$ \\
\hline \multicolumn{2}{|c|}{ Soil behavior } & Elastic & Elastic-plastic & Failure \\
\hline \multicolumn{2}{|c|}{ Soil properties } & \multicolumn{2}{|c|}{ Shear modulus, Poisson's ratio, damping } & $\begin{array}{l}\text { Angle of internal } \\
\text { friction, cohesion }\end{array}$ \\
\hline \multicolumn{2}{|c|}{ Effect of load repetition } & \\
\hline \multicolumn{2}{|c|}{ Effect of loading frequency } & \\
\hline \multirow{3}{*}{$\begin{array}{l}\text { In situ } \\
\text { measure- } \\
\text { ment }\end{array}$} & Seismic wave method & $\longrightarrow$ & & \\
\hline & In situ vibration test & $\longleftarrow$ & $\longrightarrow$ & \\
\hline & Repeated loading test & & & $\longrightarrow$ \\
\hline \multirow{3}{*}{$\begin{array}{c}\text { Laboratory } \\
\text { measure- } \\
\text { ment }\end{array}$} & Wave propagation test & $\rightarrow$ & & \\
\hline & Resonant column test & $\longleftarrow$ & $\rightarrow$ & \\
\hline & Repeated loading test & \multicolumn{3}{|c|}{$\stackrel{\longrightarrow}{\longleftrightarrow}$} \\
\hline
\end{tabular}

Figure 1. Variation in shear modulus with different shear strain levels for different geoengineering applications, in-situ tests, and laboratory tests (after Atkinson and Sallfors 1991, Mair 1993, Ishihara, 1996, Sawangsuriya et al. 2005).

2. Good agreement between stiffness measured in the laboratory and in the field is made when the laboratory specimens are at the same conditions as those in the field (Anderson and Woods 1976, Viggiani and Atkinson 1995a, Nazarian et al. 1999, Atkinson 2000).

3. Load repetition, strain rate, and loading frequency have only minor influence in the small-strain range (Iwasaki et al. 1978, Ni 1987, Bolton and Wilson 1989, Tatsuoka and Shibuya 1991, Jardine 1992, Shibuya et al. 1992, 1995, Ishihara 1996). 
4. Stiffness of geomaterials is unique for both static (monotonic) and dynamic (cyclic) loading conditions (Georgiannou et al. 1991, Jamiolkowski et al. 1994, Tatsouka et al. 1997).

5. Little or no hysteresis (stress-strain loop) exists in both slow repetitive and dynamic cyclic loading tests (Silvestri 1991).

6. Volumetric and shear deformations (or strains) are fully recoverable and the tendency of geomaterials to dilate or to contract during drained shear does not occur (Ishihara 1996).

7. Stiffness is independent of drainage since the induced strain levels are too small to cause pore water pressure to build up during undrained shear test (Ohara and Matsuda 1988, Dobry 1989, Georgiannou et al. 1991, Silvestri 1991). Pore water pressure does not build up if the shear strain amplitude is smaller than 10-2\% for sands (Dobry 1989) and $0.1 \%$ for clays (Ohara and Matsuda 1988).

\begin{tabular}{|c|c|c|c|}
\hline $\begin{array}{l}\text { Test } \\
\text { Methods }\end{array}$ & Standard & Test Principle & References \\
\hline $\begin{array}{l}\text { Soil Stiffness } \\
\text { Gauge (SSG) }\end{array}$ & $\begin{array}{l}\text { ASTM } \\
\text { D } 6758\end{array}$ & $\begin{array}{l}\text { A small dynamic force generated inside } \\
\text { the device is applied through a ring- } \\
\text { shaped foot resting on the ground } \\
\text { surface and a deflection is measured } \\
\text { using velocity sensors. The near-surface } \\
\text { stiffness of geomaterials is then } \\
\text { determined as the ratio of the applied } \\
\text { force to the measured deflection. }\end{array}$ & $\begin{array}{c}\text { Wu et al. (1998), } \\
\text { Humboldt (1999, 2000a, } \\
\text { 2000b), Fiedler et al. } \\
\text { (1998, 2000), Nelson and } \\
\text { Sondag (1999), Chen et al. } \\
\text { (1999), Siekmeir et al. } \\
\text { (1999), Hill et al. (1999), } \\
\text { Sargand et al. (2000), } \\
\text { Weaver et al. (2001), } \\
\text { Lenke et al. (2001, 2003), } \\
\text { Sargand (2001), Peterson } \\
\text { et al. (2002), } \\
\text { Sawangsuriya et al. (2002, } \\
\text { 2003, 2004) }\end{array}$ \\
\hline $\begin{array}{l}\text { Bender } \\
\text { Element }\end{array}$ & None & $\begin{array}{l}\text { Shear wave velocity is determined by } \\
\text { measuring the travel time of shear wave } \\
\text { and the tip-to-tip distance of } \\
\text { piezoceramic bender elements. The } \\
\text { corresponding shear stiffness is } \\
\text { calculated by knowing the shear wave } \\
\text { velocity and mass density of } \\
\text { geomaterial. }\end{array}$ & $\begin{array}{l}\text { Dyvik and Madshus } \\
\text { (1985), Thomann and } \\
\text { Hryciw (1990), Hryciw } \\
\text { and Thomann (1993), } \\
\text { Souto et al. (1994), Fam } \\
\text { and Santamarina (1995), } \\
\text { Nakagawa et al. (1996), } \\
\text { Viggiani and Atkinson } \\
\text { (1995b, 1997), Jovicic and } \\
\text { Coop (1998), Zeng and Ni } \\
\text { (1998), Fioravante and } \\
\text { Capoferri (2001), } \\
\text { Santamarina et al. (2001) }\end{array}$ \\
\hline
\end{tabular}




\begin{tabular}{|c|c|c|c|}
\hline $\begin{array}{l}\text { Resonant } \\
\text { Column }\end{array}$ & $\begin{array}{l}\text { ASTM } \\
\text { D } 4015\end{array}$ & $\begin{array}{l}\text { Resonant frequency is measured and is } \\
\text { related to the shear wave velocity and } \\
\text { the corresponding shear stiffness. }\end{array}$ & $\begin{array}{c}\text { Wilson and Dietrich } \\
\text { (1960), Hardin and Music } \\
\text { (1965), Hardin (1970), } \\
\text { Drnevich (1977), } \\
\text { Drnevich et al. (1978), } \\
\text { Edil and Luh (1978), } \\
\text { Isenhower (1980), } \\
\text { Drnevich (1985), Ray and } \\
\text { Woods (1988), Morris } \\
\text { (1990), Lewis (1990), } \\
\text { Cascante et al. (1998) }\end{array}$ \\
\hline \begin{tabular}{|l|} 
Pulse \\
Transmission \\
(Ultrasonic \\
Pulse)
\end{tabular} & $\begin{array}{l}\text { ASTM } \\
\text { C } 597\end{array}$ & $\begin{array}{l}\text { Elastic wave velocity is determined by } \\
\text { measuring a travel time of either } \\
\text { compressional wave or shear wave } \\
\text { arrivals and the distance between } \\
\text { ultrasonic transducers made of } \\
\text { piezoelectric materials. The stiffness of } \\
\text { geomaterial is calculated based on an } \\
\text { elastic theory. }\end{array}$ & $\begin{array}{l}\text { Lawrence (1963), Nacci } \\
\text { and Taylor (1967), } \\
\text { Sheeran et al. (1967), } \\
\text { Woods (1978), Nakagawa } \\
\text { et al. (1996), Yesiller et al. } \\
\text { (2000) }\end{array}$ \\
\hline $\begin{array}{l}\text { Seismic } \\
\text { Reflection }\end{array}$ & None & $\begin{array}{l}\text { Travel time of seismic waves reflected } \\
\text { from subsurface interfaces following the } \\
\text { law of reflection is measured so that the } \\
\text { elastic wave propagation velocity and } \\
\text { the corresponding stiffness of } \\
\text { geomaterial are determined. }\end{array}$ & $\begin{array}{l}\text { Kramer (1996), Sharma } \\
\text { (1997), Frost and Burns } \\
\text { (2003) }\end{array}$ \\
\hline $\begin{array}{l}\text { Seismic } \\
\text { Refraction }\end{array}$ & $\begin{array}{l}\text { ASTM } \\
\text { D } 5777\end{array}$ & $\begin{array}{l}\text { Travel time of seismic refracted waves } \\
\text { when they encounter a stiffer material } \\
\text { (higher shear wave velocity) in the } \\
\text { subsurface interface following the law } \\
\text { of refraction (Snell's law) is measured } \\
\text { so that the elastic wave propagation } \\
\text { velocity and the corresponding } \\
\text { stiffness of geomaterial are } \\
\text { determined. }\end{array}$ & $\begin{array}{l}\text { Kramer (1996), Sharma } \\
\text { (1997), Frost and Burns } \\
\text { (2003) }\end{array}$ \\
\hline $\begin{array}{l}\text { Spectral } \\
\text { Analysis of } \\
\text { Surface } \\
\text { Waves } \\
(\text { SASW) }\end{array}$ & None & $\begin{array}{l}\text { Surface (Rayleigh) wave velocity varied } \\
\text { with frequency is measured by utilizing } \\
\text { the dispersion characteristics of surface } \\
\text { wave and the fact that surface waves } \\
\text { propagate to depths that are } \\
\text { proportional to their wavelengths or } \\
\text { frequencies in order to determine the } \\
\text { stiffness of subsurface profiles. }\end{array}$ & $\begin{array}{c}\text { Nazarian and Stokoe } \\
\text { (1987), Sanchez-Salinero } \\
\text { et al. (1987), Rix and } \\
\text { Stokoe (1989), } \\
\text { Campanella (1994), } \\
\text { Nazarian et al. (1994), } \\
\text { Wright et al. (1994), } \\
\text { Mayne et al. (2001) }\end{array}$ \\
\hline
\end{tabular}




\begin{tabular}{|c|c|c|c|}
\hline \begin{tabular}{|l} 
Seismic \\
Cross-Hole
\end{tabular} & $\begin{array}{l}\text { ASTM } \\
\text { D } 4428\end{array}$ & $\begin{array}{c}\text { Measurement of wave propagation } \\
\text { velocity either compressional or shear } \\
\text { wave from one subsurface boring to } \\
\text { other adjacent subsurface borings in a } \\
\text { linear array. The seismic wave is } \\
\text { generated by various means so that the } \\
\text { elastic waves propagate in the } \\
\text { horizontal direction through } \\
\text { the geomaterial and are } \\
\text { detected by the geophones located } \\
\text { in the other hole. }\end{array}$ & $\begin{array}{l}\text { Stokoe and Woods (1972), } \\
\text { Stokoe and Richart (1973), } \\
\text { Anderson and Woods } \\
\text { (1975), Hoar and Stokoe } \\
\text { (1978), Campanella } \\
\text { (1994), Mayne et al. } \\
\text { (2001), Frost and Burns } \\
\text { (2003) }\end{array}$ \\
\hline $\begin{array}{l}\text { Seismic } \\
\text { Down-Hole } \\
\text { or Up-Hole }\end{array}$ & None & $\begin{array}{l}\text { Compressional and/or shear waves } \\
\text { propagating vertically in a single } \\
\text { borehole are monitored. The travel time } \\
\text { of compressional and/or shear waves } \\
\text { from the source to receiver(s) is } \\
\text { measured. The wave propagation } \\
\text { velocity at any depths is obtained from } \\
\text { a plot of travel time versus depth. }\end{array}$ & $\begin{array}{c}\text { Richart (1977), } \\
\text { Campanella (1994), } \\
\text { Ishihara (1996), Mayne et } \\
\text { al. (2001), Frost and Burns } \\
\text { (2003) }\end{array}$ \\
\hline $\begin{array}{l}\text { Seismic Cone } \\
\text { Penetration }\end{array}$ & None & $\begin{array}{l}\text { Similar to the seismic down-hole test, } \\
\text { except that no borehole is required. The } \\
\text { profile of shear wave velocity is } \\
\text { obtained in a same manner as the } \\
\text { seismic down-hole test. The receiver is } \\
\text { located in the cone }\end{array}$ & $\begin{array}{l}\text { Campanella et al. (1986), } \\
\text { Robertson et al. (1986), } \\
\text { Baldi et al. (1988), } \\
\text { Campanella (1994), } \\
\text { Kramer (1996), Mayne } \\
\text { (2001), Frost and Burns } \\
\text { (2003) }\end{array}$ \\
\hline
\end{tabular}

Table 1. Summary of wave propagation methods for determining stiffness of geomaterials.

In particular, pulse transmission method using piezoelectric transducers have been commonly used to monitor P- and S-wave propagation in many different types of geomaterials (Lawrence 1963, Sheeran et al. 1967, Woods 1978, Yesiller et al. 2000). In spite of its common use, such method has several shortcomings. For instance, weak transmitted wave signals, poor coupling between transducer and medium, near field effects, and high operating frequencies reduce the signal-to-noise ratio of the collected signals exacerbating the difficulties in interpreting the waveforms generated with these transducers (SanchezSalinero et al. 1986, Brignoli et al. 1996, Nakagawa et al. 1996, Ismail and Rammah 2005). A number of studies on the use of bender elements in wave-based technique has overcome many of the aforementioned problems and recently become a very popular method to measure the S-wave velocity and small-strain shear modulus (Go) and their evolution with changes in effective stresses, water content, and cementation (Dyvik and Madshus 1985, Thomann and Hryciw 1990, Souto et al. 1994, Fam and Santamarina 1995, Cho and Santamarina 2001, Pennington et al. 2001, Mancuso et al. 2002, Zeng et al. 2002, Lee and Santamarina 2005). 
A bender element test utilizes a pair of two-layer piezoelectric ceramic materials for transmitting and receiving S-waves (Shirley 1978). Bender elements are widely used to determine the wave velocity as S-wave pass through a geomaterial. Because the movement of a bender element is relatively small, when it is energised, the resulting sample displacements are tiny. Thus, the shear modulus obtained from this device can be defined as the shear modulus in the small-strain region. The first application of bender elements in laboratory geotechnical testing was by Shirley and Hampton (1978). Dyvik and Madshus (1985) also measured Go in laboratory tests using bender elements which were installed in a top cap and a pedestal of an oedometer at the Norwegian Geotechnical Institute. Since then much research has been carried out using bender elements in triaxial apparatus, e.g. Viggiani 1992, Jovicic 1997, and Pennington 1999, along with their interpretation techniques of the testing results, e.g. Viggiani and Atkinson 1995 and Jovicic et al. 1996. Nowadays, bender elements are widely used to determine the wave velocity as shear wave pass through a sample.

\section{Bender element measurement and instrumentation system}

A pair of bender elements (i.e., one is a transmitter and another is a receiver) is utilized in the shear wave (S-wave) measurement. Bender elements act both as actuators and sensors that they distort or bend when subjected to a change in voltage and generate a voltage when are distorted or bent. Mounted as cantilever beams, bender elements are protruded a small distance into a specimen to provide robust coupling and induce elastic disturbances. During the excitation of bender elements, two types of mechanical waves are generated: compression (P) and shear (S) waves (Santamarina et al. 2001).

Typical configuration and electrical wiring for transmitting and receiving elements are illustrated in Fig. 2. A bender element can be tailor made in accordance with the testing apparatus and requirement (Sawangsuriya et al. 2008b). Fig. 3 illustrates an example of a series-connected piezoelectric ceramic bender element with the dimensions of 6.4-mm wide, 11.0-mm long, and 0.6-mm thick. Thin coaxial cables are soldered to the conductive bender element surfaces and their exposed electric wiring is completely coated with thinned polyurethane in order to provide electrical insulation. Typically after insulating with polyurethane, the bender elements can be coated with a conductive silver painting that creates an electric shield. The shield must be grounded to minimize electrical noise and to avoid electrical cross-talk between source and receiver. As also illustrated in Fig. 3, a custom made aluminum bolt-clamp anchoring system can be used to create a rigid cantilever system for supporting and accommodating the bender element. By using this anchoring system, one third of the bender element length $(\sim 4 \mathrm{~mm})$ is anchored in the housing and is rigidly clamped by screws. The bender element-anchoring system can be directly mounted on opposite ends of the specimen such that the S-wave propagating longitudinally was sent and received (Sawangsuriya et al. 2008b).

The transmitting bender element produces an S-wave which propagates through a medium when it is excited by an applied voltage signal. This S-wave impinges on the receiving 
bender element, causing it to bend, which in turn produces a very small voltage signal. Fig. 4 illustrates typical electrical input and output signals from the transmitting and receiving bender elements. Fig. 5 illustrates a modeled input electrical step function, a modeled source bender element response and the receiver bender element response. The true input signal is somewhat significantly different from the signal generated by the signal generator. This is due to the fact that the response of the source bender element is controlled by the elastic properties of the bimorph, the cantilever length, the support properties (i.e., fixity), and the elastic properties of the surrounding medium (Lee and Santamarina 2005). Furthermore, the receiver bender element's response is governed not only by the stiffness, attenuation and dispersive properties of the medium but also by the distance between source and receiver bender elements, the wavelength, the distance to other boundaries, and the generation of reflected waves (Sawangsuriya et al. 2006, Arroyo et al. 2006).

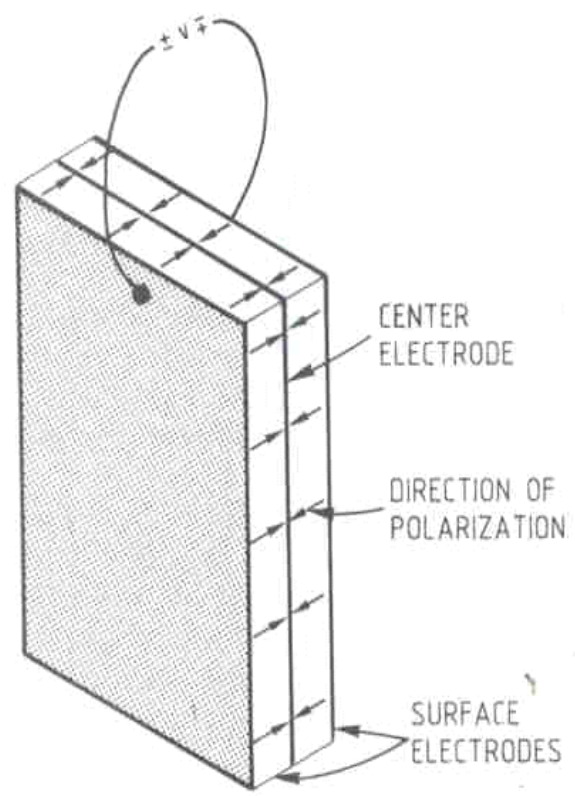

(a)

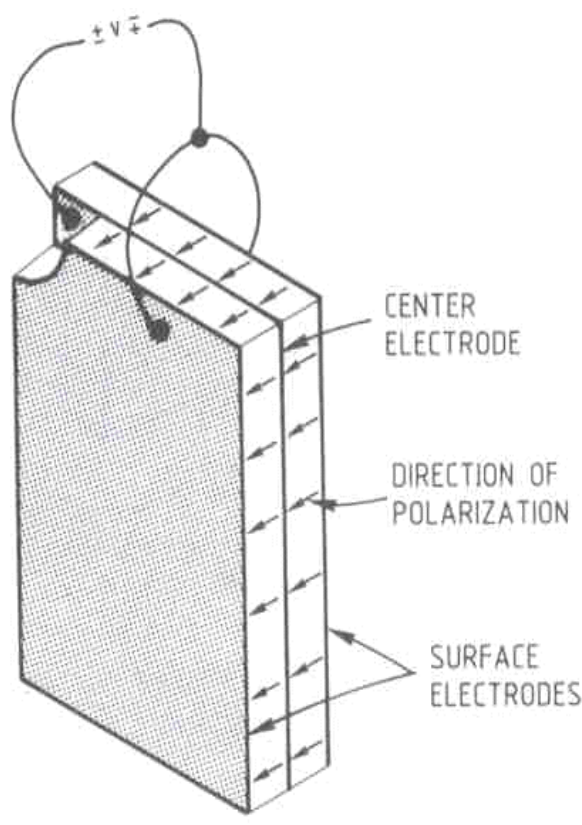

(b)

Figure 2. Two types of piezoceramic bender elements: (a) series connected and (b) paralleled connected (Dyvik and Madshus 1985). 


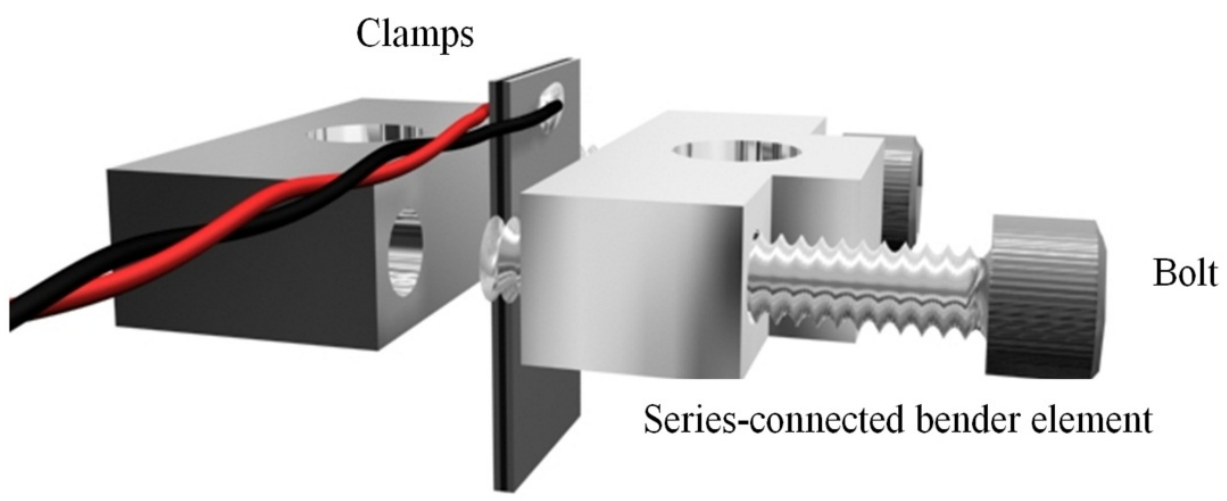

Figure 3. A 3-D drawing of bender element housing (Sawangsuriya et al. 2008b).

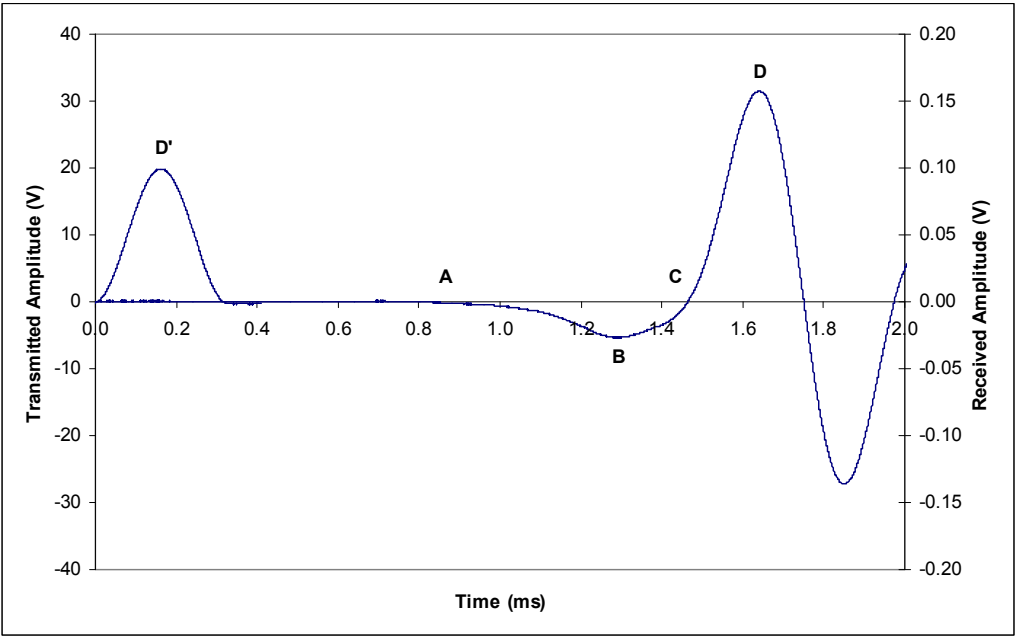

Figure 4. Typical input and output signals from the transmitting and receiving bender elements (Sukolrat 2007). 


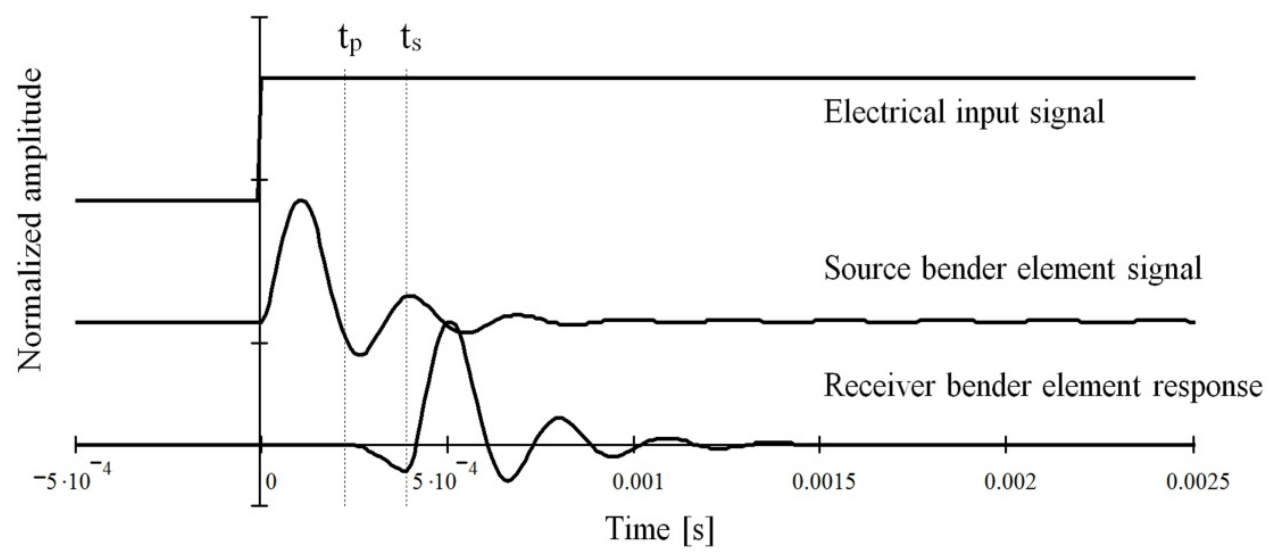

Figure 5. Modeled input electrical step function, signal generated by the source bender element and output signals from the source and receiving bender elements (Received signal modeled using SanchezSalinero et al. 1986- Model parameters: wave velocities $V_{s}=200 \mathrm{~m} / \mathrm{s}$ and $\mathrm{V}_{\mathrm{p}}=310 \mathrm{~m} / \mathrm{s}$, and damping $\mathrm{D}=0.005$ ) (Sawangsuriya et al. 2006).

Once these boundary and scale effects are evaluated and their effects are considered, the travel time between source and receiver bender elements can be determined. The recorded traces provide a means to measure the S-wave travel time, calculate the S-wave velocity, and evaluate the corresponding shear modulus (if the density is known). By measuring the travel time of the $\mathrm{S}$-wave $\left(\mathrm{t}_{\mathrm{s}}\right)$ and the tip-to-tip distance between transmitting and receiving bender element $\left(L^{\prime}\right)$, the $S$-wave velocity of the specimen $\left(V_{s}\right)$ is obtained as:

$$
V_{s}=\frac{L^{\prime}}{t_{s}}
$$

The instrumentation system for the bender element test consists of a pair of bender elements, function generator, signal amplifier, voltage divider for the input signals and digital oscilloscope, signal amplifier/filter and digital oscilloscope. Fig. 6 illustrates a schematic diagram of the bender element instrumentation system and that of an automatic multiplex bender element acquisition system when more than three pairs of bender elements are installed to a sample. A signal generator is commonly used to generate an input signal to the transmitting bender element. It is also noteworthy that the square-wave input signal gives the clearest response regardless of sample's stiffness because it includes all frequencies, which is advantageous when the resonant frequency of the bender elementmedium system is unknown (Kawaguchi et al. 2001, Lee and Santamarina 2005). 


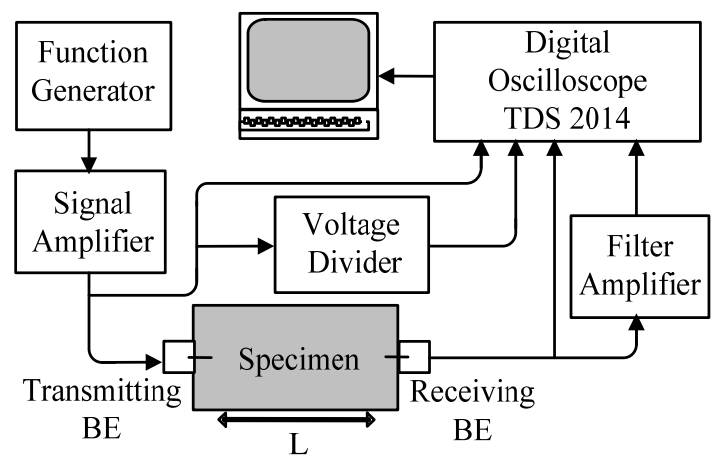

(a)

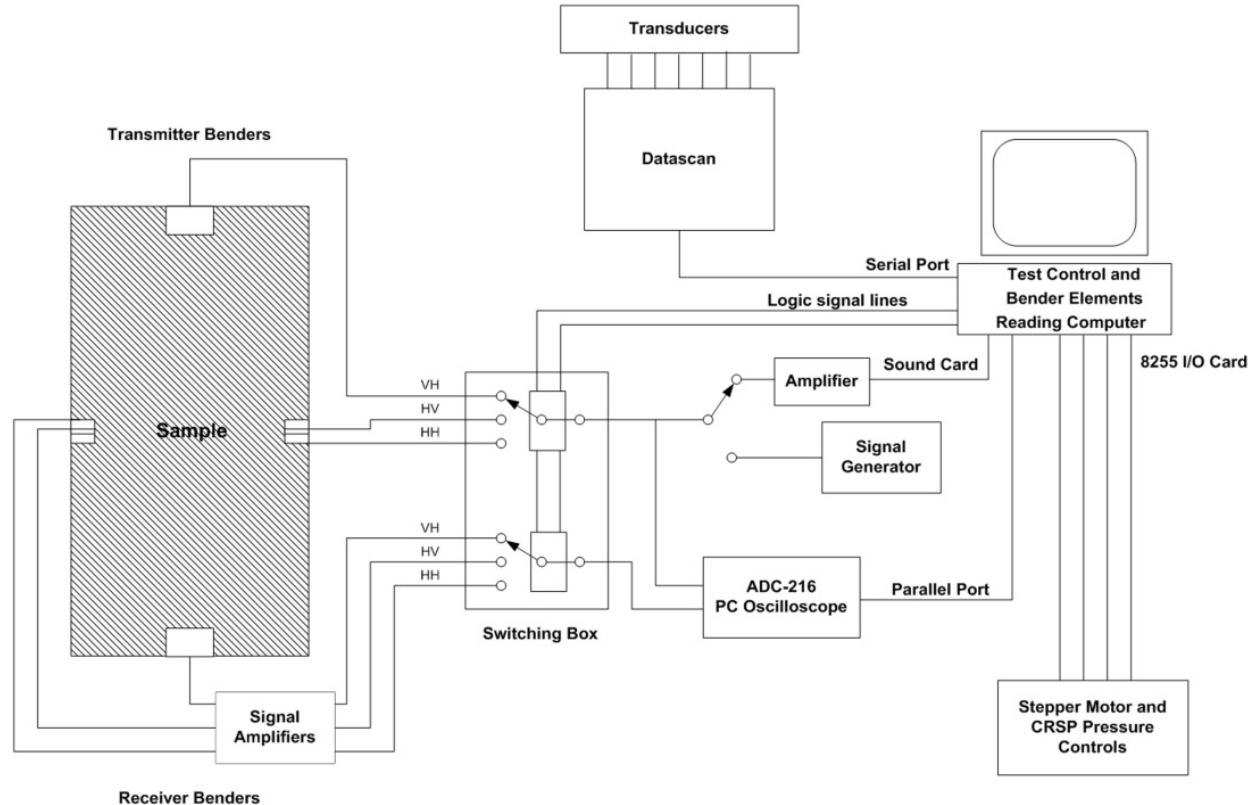

(b)

Figure 6. Schematic diagram of the bender element instrumentation system: (a) manual system for one direction of wave propagation (Sawangsuriya et al. 2006), (b) automatic multiplexing system for triaxial sample (Sukolrat 2007).

\section{Collection and interpretation of bender element measurement data in geomaterials}

Although S-wave measurements using bender elements are promising, the convenience of bender element tests is limited by subjectivity associated with identifying wave travel time arrivals. The effect of distances to boundaries and between source and receiver plays an 
important role in the evaluation of wave propagation test data. For example when S-waves are created in a bender element wave propagation test, reflection and refraction from boundaries may produce waves other than direct S-waves; near-field effect may obscure the S-wave arrival; or wave attenuation and dispersion may prevent the proper identification of multiple reflections (Sanchez-Salinero et al. 1986, Fratta and Santamarina 1996). Sawangsuriya et al. (2006) performed a series of experimental studies to explore and to establish the limits to minimize the boundary effects in the wave propagation experiments. The experimental results are presented as simple dimensionless ratios that can provide guidelines for the design and interpretation of the wave propagation experiments as the following:

\section{Near-field effects}

Distinguishing S-wave arrivals in the near-field is difficult since the arrival of the S-wave may be obscured by other wavefronts that propagate at higher velocities (e.g. P-wave velocity - Sanchez-Salinero et al. 1986, Lee and Santamarina 2005). This effect becomes significant especially at closer distances between sources and receivers. Sanchez-Salinero et al. (1986) developed a closed-form solution for longitudinal and transverse motions in linear-elastic and homogeneous media. Fig. 7a shows the arrivals for distances between source and receiver (L) equal to $1,2,3,4,6$, and 8 shear-wave wavelengths $\left(\lambda_{s}\right)$. Note that for greater relative source-receiver distances $\left(\mathrm{L} / \lambda_{\mathrm{s}}\right)$, the separation between $\mathrm{P}$ - and $\mathrm{S}$-wave arrivals increases, the amplitude of the transverse displacement caused by the P-wave decreases and the S-wave arrival is better evaluated. To clearly separate the P- and S-wave arrivals, $\mathrm{L} / \lambda_{\mathrm{s}}$ must be greater than 4 . However, this ratio also depends on the material damping. Understanding of the near-field effects may help interpreting both P-and S-waves arrival times which can also be used to evaluate the elastic modulus and Poisson's ratio. According to the wave propagation experiments by Sawangsuriya et al. (2006), wave propagation results were obtained using long cylindrical Kaolinite specimens $(77.5 \mathrm{~mm}$ diameter) that were trimmed to different heights and hence different source-receiver distances. Since the specimens were identical, the slope of the measured travel time versus distance was used to calculate the P- and S-wave velocities (see Fig. 7b). The calculated Poison's ratio $(v)$ is 0.17 . As the source-receiver distance increases, the P-wave arrival is more difficult to determine (Fig. 7a), for this reason there are less P-wave arrival time data points at greater source-receiver distances in Fig. $7 \mathrm{~b}$. It is therefore recommended that the minimum source-receiver distance (L) must be at least three times the wavelength $\left(\lambda_{\mathrm{s}}\right)$ (greater for large damping ratios) to facilitate the interpretation of the S-wave arrivals.

\section{Boundary effects - reflection}

When a bender element deflects, it generates S-waves in the direction of the bender element plane and P-waves in the direction normal to the bender element plane (Santamarina et al. 2001). Therefore, the presence of lateral boundaries may cause the reflected P-waves to arrive faster than direct $\mathrm{S}$-waves hindering the proper evaluation of $\mathrm{S}$-wave velocities. The difference in travel time arrivals depends on the Poisson's ratio $(v)$ of the geomaterial (Lee 
and Santamarina 2005). In 3-D arrangements of sources and receivers, the limiting separations can be expressed as a function of dimensionless ratios $\mathrm{H} / \mathrm{L}$ and $\mathrm{R} / \mathrm{L}$ and the Poisson's ratio as illustrated in Fig.8. Note that the normalized distances below the curves are the acceptable distances where the S-wave arrives earlier than the reflected P-wave. It is therefore important that depending on the Poisson's ratio of the geomaterial, the relative distance between sources and receivers and to the boundaries $(\mathrm{H} / \mathrm{L}$ and $\mathrm{R} / \mathrm{L})$ must be limited to avoid possible P-wave reflection interferences.

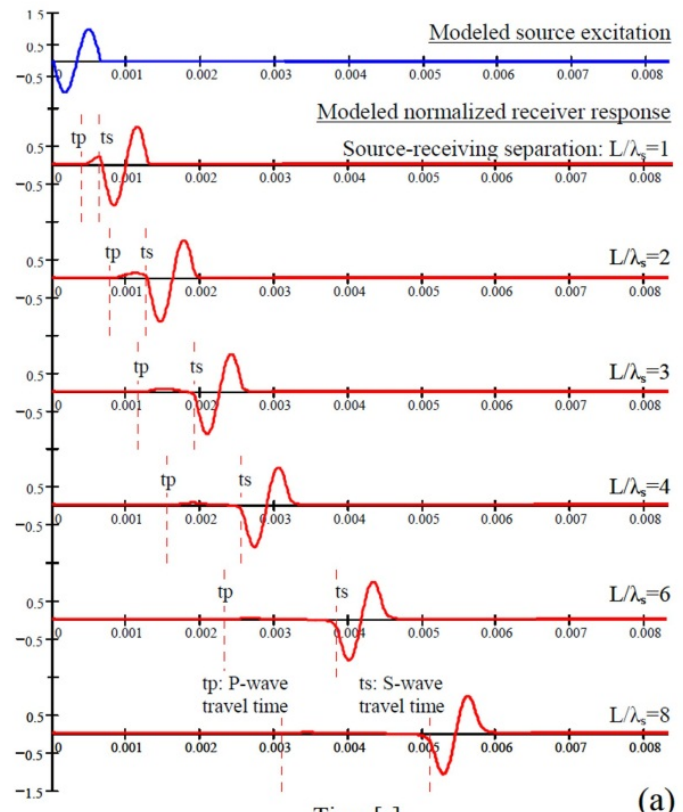

Time $[\mathrm{s}]$

$$
\begin{aligned}
& \text { P-wave velocity: } V_{P}=\sqrt{\frac{M}{\rho}}=\sqrt{\frac{E}{\rho} \frac{1-v}{(1+v)(1-2 v)}} \\
& \text { S-wave velocity: } V_{S}=\sqrt{\frac{G}{\rho}}=\sqrt{\frac{E}{\rho} \frac{1}{2(1+v)}} \\
& \text { Poisson's ratio: } \quad v=\frac{\frac{1}{2}\left(\frac{V_{p}}{V_{S}}\right)^{2}-1}{\left(\frac{V_{P}}{V_{S}}\right)^{2}-1}
\end{aligned}
$$

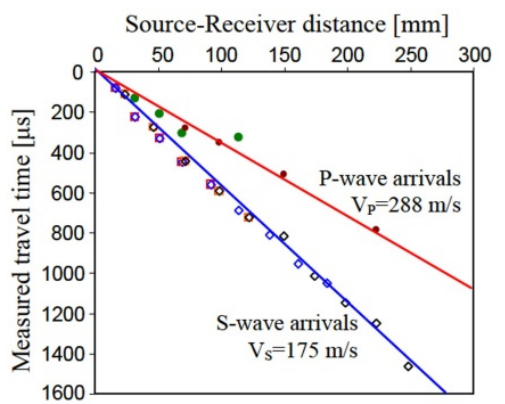

(b)

Figure 7. Near-field effects: (a) normalized receiver response (transverse particle motion) with increasing source-receiver separation (model parameters: $\mathrm{V}_{\mathrm{p}}=288 \mathrm{~m} / \mathrm{s}, \mathrm{V}_{\mathrm{s}}=175 \mathrm{~m} / \mathrm{s}$, damping $\mathrm{D}=0.01$ closed-form solution by Sanchez-Salinero et al. 1986), and (b) measured P- and S-waves travel times in Kaolinite specimens (Sawangsuriya et al. 2006). Note: $\mathrm{M}=$ constraint modulus, $\mathrm{G}=$ shear modulus, $\mathrm{E}=$ Young's modulus, $\mathrm{Q}=$ mass density.

\section{Boundary effects - refraction}

As the separation between source and receiver increases, refracted waves may travel along rigid boundaries (having higher velocities) masking the S-wave arrivals. This phenomenon can be observed when the test specimen is confined within a rigid wall container. When monitoring S-waves, the velocity is calculated by an assumed straight ray travel length and the first arrival time. However, the presence of the rigid boundary may mask the arrival of the direct S-wave if a refracted wave arrives first. This phenomenon was observed by using specimens prepared inside the cylindrical rigid wall container where the source-receiver 
distance and the distance to the wall varied (Sawangsuriya et al. 2006). Results matched well with a simple refraction model used to determine the shortest travel time from the two possible wave paths. A sketch of the model and a summary of experimental results are shown in Fig. 9. Results suggest that for a given medium and PVC wall having finite wave velocities, the bender elements need to be placed at a minimum distance (d) greater than 0.4 $\mathrm{L}$ to avoid receiving refracted signals. As a consequence, it is recommended that with the presence of rigid boundaries, the distance of bender elements to the boundary (d) shall be greater than approximately $0.4 \mathrm{~L}$ to avoid refracting wave from arriving first.
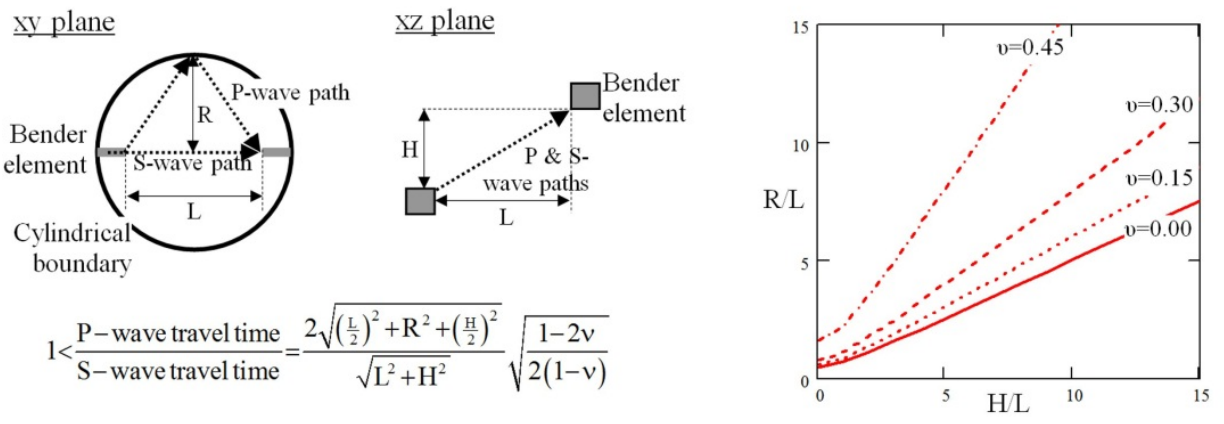

Figure 8. Limiting distances to avoid reflected P-wave arrivals when testing with boundaries. The lines in the plot represent the upper limits, the recommended test dimensions should fall under these lines (Sawangsuriya et al. 2006).
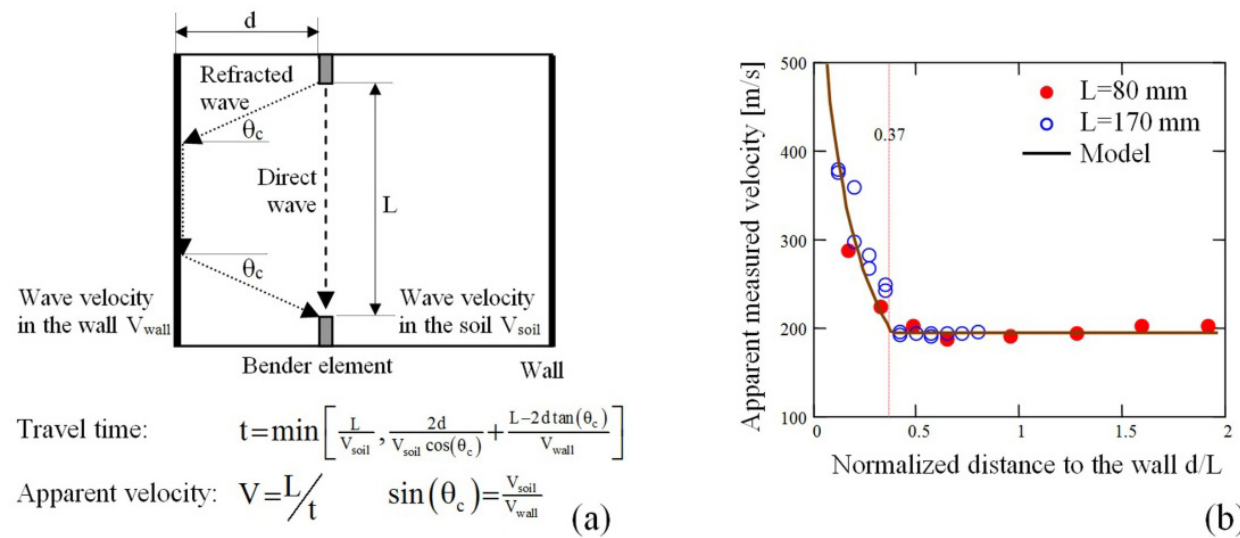

Figure 9. (a) Sketch of the test setup and the model for data evaluation and (b) experimental results from Kaolinite specimens (water content $=22 \%$, unit weight $\left.=9.7 \mathrm{kN} / \mathrm{m}^{3}\right)($ Sawangsuriya et al. 2006).

\section{Identifying wave travel time arrivals}

A selection of the travel time for a wave travelling from a transmitter bender to a receiver bender has been controversial. Generally, the travel time can be determined either in the 
time domain or in the frequency domain. In the time-domain method, the travel time of the S-wave is monitored by plotting recorded signal with time. The S-wave velocity is then calculated if the tip-to-tip distance between the transmitting and receiving bender elements is known (Dyvik and Madshus 1985; Viggiani and Atkinson 1995). In general, the signals may be different from those in Figs. 4 and 5, possibly due to the stiffness of the sample, the boundary conditions, the test apparatus, the degree of fixity of the bender element into the platen or housing, the elastic properties of the bimorph, the cantilever length, the support properties (i.e., fixity), and the elastic properties of the surrounding medium as aforementioned. Once these boundary and scale effects are evaluated, and their effects are considered, the travel time between the transmitter and the receiver benders can be determined. The S-wave arrival corresponds to point C (Fig. 4) is typically chosen for the determination of the travel time in order to avoid the near-field effect caused by the arrival of energy with P-wave velocity (point A in Fig. 4 - Sanchez-Salinero et al. 1986; Kawaguchi et al. 2001; Lee and Santamarina 2005).

In the frequency-domain method, the transmitter sends a continuous sinusoidal wave at a single frequency through the sample to the receiver, and the phase shift between the two waves is measured. By varying the frequency, the phase delay of the transmitted and received signals can be observed, and the frequencies may be found when they are exactly in-phase and exactly out-of-phase when the phase differences are exact multiple $N$ of $\pi$. The gradient of the plot between wave number $(\mathrm{N})$ against frequency gives the group travel time. This is also called as $\pi$-point method. Similar results may be obtained using a sine sweep instead of a continuous wave of a single frequency. The Automatic Bender Elements Testing System (ABETS) program has been developed and uses phase-delay method to determine the shear wave velocities from bender element tests (Greening and Nash 2004). The principle of the ABETS is to send a sine wave pulse of continuously varying frequency generated by a soundcard in a computer through the sample. The signals from the transmitter and the receiver are collected and analysed by embedded Fast Fourier Transform (FFT) analysis. By selecting the range of frequencies for which the coherence is close to unity which indicates high quality signal that there is no interference at that transmitted frequency, a linear fit to the unwrapped phase data is used to determine the group's travel time within selected frequency range.

\section{Evaluation of S-wave velocity}

The S-wave velocity in particulate geomaterials depends on the state and history of the effective stresses, void ratio, degree of saturation, and type of particles. Based on experimental evidence and analytical studies, the velocity-effective stress relationship for granular geomaterials is expressed as a power function having two physically-meaningful parameters: a coefficient $\alpha$ and an exponent $\beta$. These parameters represent the S-wave velocity at a given state of stress and its variation with stress changes. The velocity-stress power relationship for granular media under isotropic loading is expressed as (Roesler 1979, White 1983): 


$$
V_{s}=\alpha\left(\frac{\sigma_{o}^{\prime}}{p_{r}}\right)^{\beta}
$$

where $\mathrm{V}_{\mathrm{s}}$ is the S-wave velocity, $\sigma^{\prime}{ }_{\mathrm{o}}$ is the isotropic effective stress, $\mathrm{p}_{\mathrm{r}}=1 \mathrm{kPa}$ is a reference stress, $\alpha$ and $\beta$ are experimentally determined parameters. Fig. 10 illustrates an example of the velocity-stress relationship as determined by S-wave velocity measurements at different stress states for dry medium sand prepared by different methods exhibits a power function (see Fig. 10) along with the experimentally determined coefficient $\alpha$ and exponent $\beta$ (Sawangsuriya et al. 2007a). As shown in Fig. 10, for a dry medium sand subjected to isotropic loading, the velocity-stress power relation in Eq. (2) closely fits the data and as expected, the S-wave velocity increases as the confining pressure increases.

Several researchers have attempted to quantify the physical meaning of these experimentally determined parameters. Duffy and Mindlin (1957), Hardin and Black (1968), Santamarina et al. (2001), Fernandez and Santamarina (2001), and Fratta and Santamarina (2002) described the physical meaning of the parameters $\alpha$ and $\beta$ : the coefficient $\alpha$ relates to the type of packing (i.e., void ratio or coordination number), the properties of the material, and fabric changes, while the exponent $\beta$ relates to the effects of contact behavior. Both parameters indicate the effects of stress history, cementation and rock weathering in the formation. For example, dense sands, overconsolidated clays, and soft rocks have higher coefficient $\alpha$ and lower exponent $\beta$. In case of loose sands, normally consolidated clays, and clays with high plasticity, the coefficient $\alpha$ becomes lower while the exponent $\beta$ becomes higher. Santamarina et al. (2001) suggested an inverse relationship between $\alpha$ and $\beta$ values for various granular media, ranging from sands and clays to lead shot and steel spheres:

$$
\beta \approx 0.36-\frac{\alpha}{700 \frac{m}{s}}
$$

In addition, Hardin and Black (1968) suggested that the coefficient $\alpha$ can be separated into two coefficients: one accounts for the grain characteristic (or nature of grains), and the other accounts for the properties of the packing (i.e., void ratio or coordination number). The separation into these different components is justified on particulate material models. For example for random particles of uniform spheres with Hertzian contacts, the relationship between isotropic stresses and S-wave velocity is (Chang et al. 1991, Santamarina et al. 2001):

$$
V_{s}=\underbrace{\left(\frac{\sqrt{\pi}}{4 \cdot \rho^{\prime}} \cdot \frac{5-4 v^{\prime}}{2-v^{\prime}}\right)^{1 / 2}\left(\frac{G^{\prime}}{1-v^{\prime}}\right)^{1 / 3}}_{\text {particle properties }} \cdot \underbrace{\left[\frac{1.7-e}{(1+e)^{5 / 2}}\right]^{1 / 3}}_{\text {packing properties }} \cdot \underbrace{\left(\sigma_{o}^{\prime}\right)^{1 / 6}}_{\begin{array}{c}
\text { effective } \\
\text { stress }
\end{array}}
$$

where $Q^{\prime}, G^{\prime}$, and $v^{\prime}$ are the density, shear modulus and Poisson's ratio of the particles. This equation is derived assuming that the number of contacts per particle or coordination number $C_{n}$ is related to the void ratio e by the following equation (Chang et al. 1991): 


$$
C_{n}=13.28-8 e
$$

Experimentally, the velocity-stress power relation is re-written as:

$$
V_{s}=A \cdot F(e) \cdot\left(\frac{\sigma_{o}^{\prime}}{p_{r}}\right)^{\beta}
$$

where $\mathrm{A}$ is a fitting parameter which accounts for the properties of the grains and the function F(e) depends on the initial void ratio e of the geomaterial (Mitchell and Soga 2005). For round-grained particles, Hardin and Black (1968) proposed the following function:

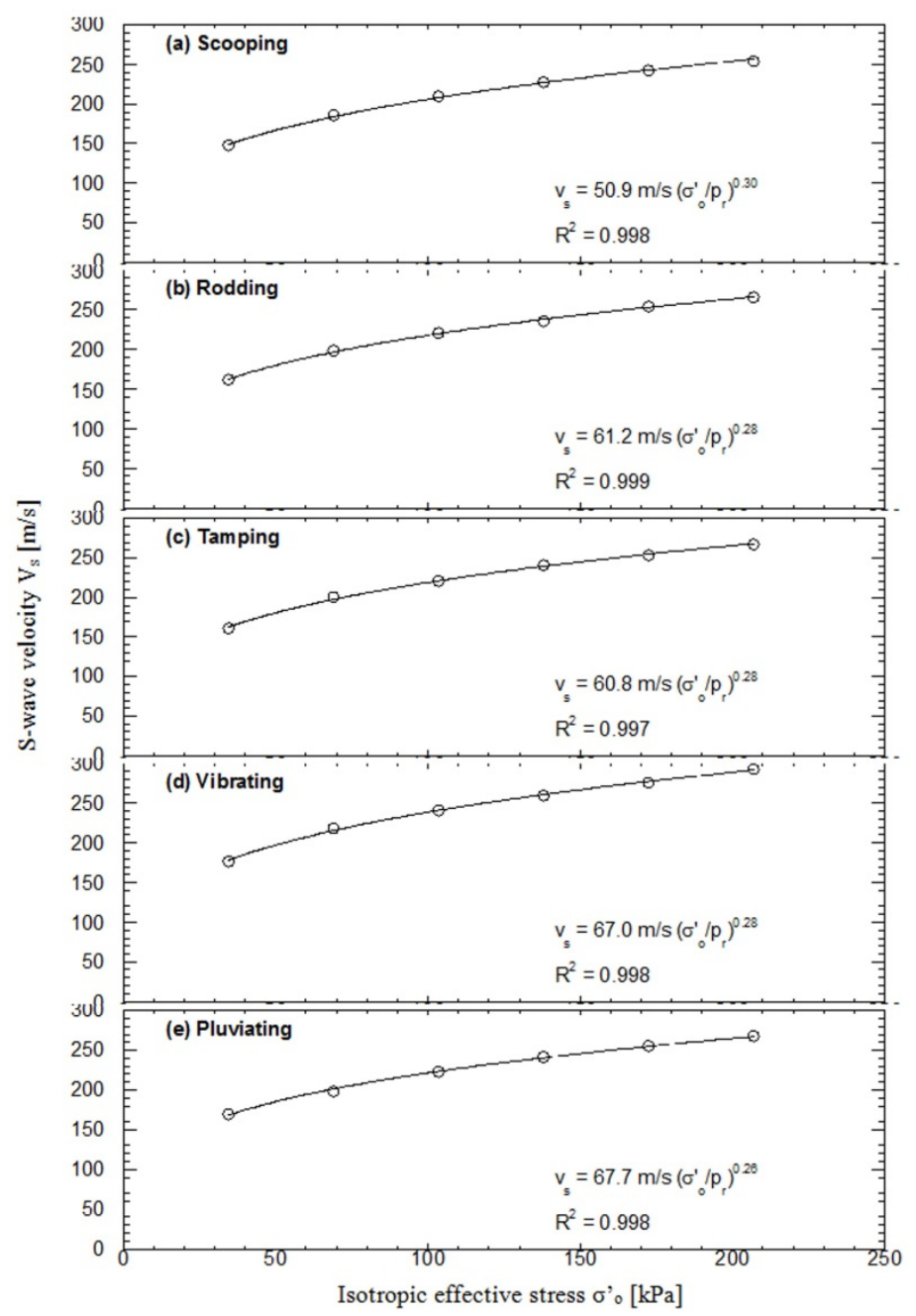

Figure 10.Velocity-stress response of specimen prepared with different methods (Sawangsuriya et al. 2007a). 


$$
F(e)=\frac{(2.17-e)^{2}}{1+e}
$$

The evaluation of S-wave velocity using bender elements has been commonly performed on oedometer and standard triaxial samples. Normally, the top and bottom caps of an oedometer cell and a conventional triaxial cell are modified to incorporate bender elements and their electrical connections (see Fig. 11 - Sawangsuriya et al. 2007a). As shown in Fig. 11, the evaluation of S-wave velocity using bender elements is performed on standard triaxial specimens and subjected to isotropic loading. The top and bottom caps of a conventional triaxial cell are modified to incorporate bender elements and their electrical connections (see Fig. 11a). Examples of S-wave traces from bender element tests are shown in Fig. 12 along with the S-wave arrival as indicated by the arrows. As shown in Fig. 12, the S-wave arrival increases with confining pressure.

Laterally mounted benders were also used in triaxial apparatus (Pennington 1999). The horizontal pairs of bender elements are installed to study the anisotropy of the sample (see Fig. 13- Sukolrat 2007). In horizontal bender system, two similar bender elements were mounted orthogonally; one pair is used for S-wave transmitters and the other pair is for Swave receivers. The bender elements are placed diagonally opposite one another and oriented so that the shear stiffness in both $\mathrm{HV}$ and $\mathrm{HH}$ directions are synchronized (depending on different polarization direction).

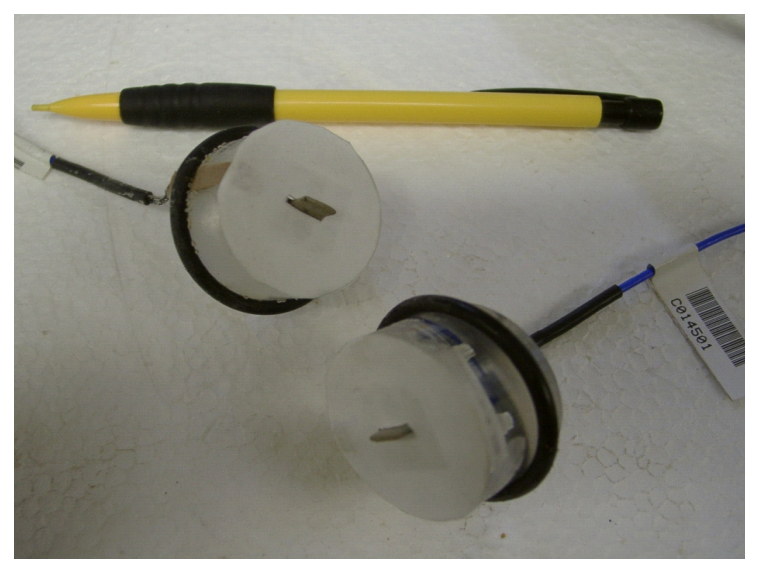

(a)

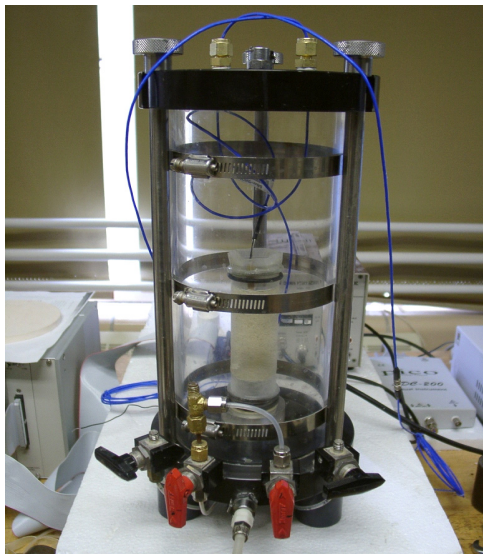

(b)

Figure 11. Modified triaxial cell with bender element measurement system: (a) details of bender elements and (b) assembled modified triaxial cell (Sawangsuriya et al 2007a). 


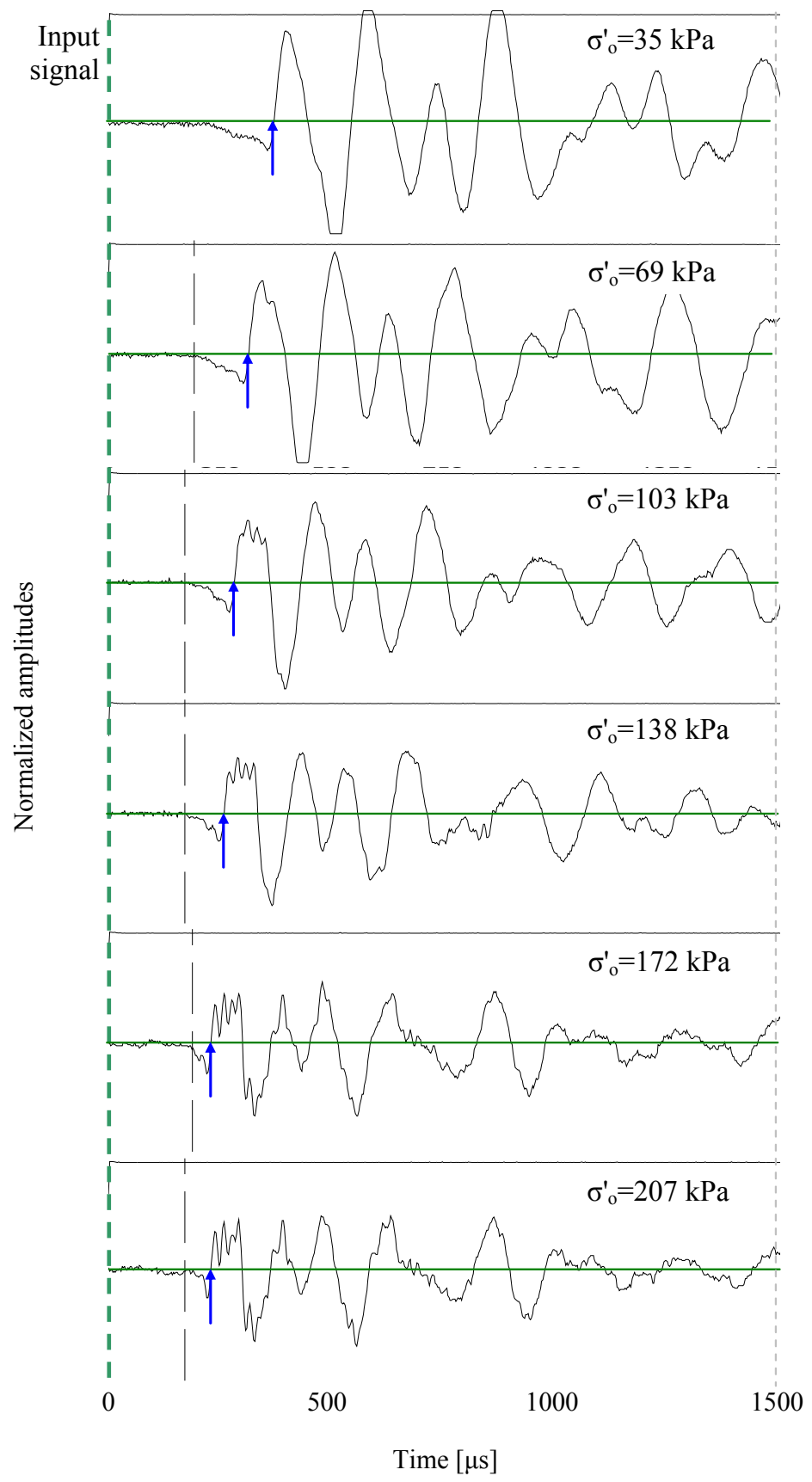

Figure 12. S-wave traces from bender element tests. The arrow corresponds to the estimated S-wave arrival. The first deflection corresponds to the near-field effect (Sawangsuriya et al. 2007a). 


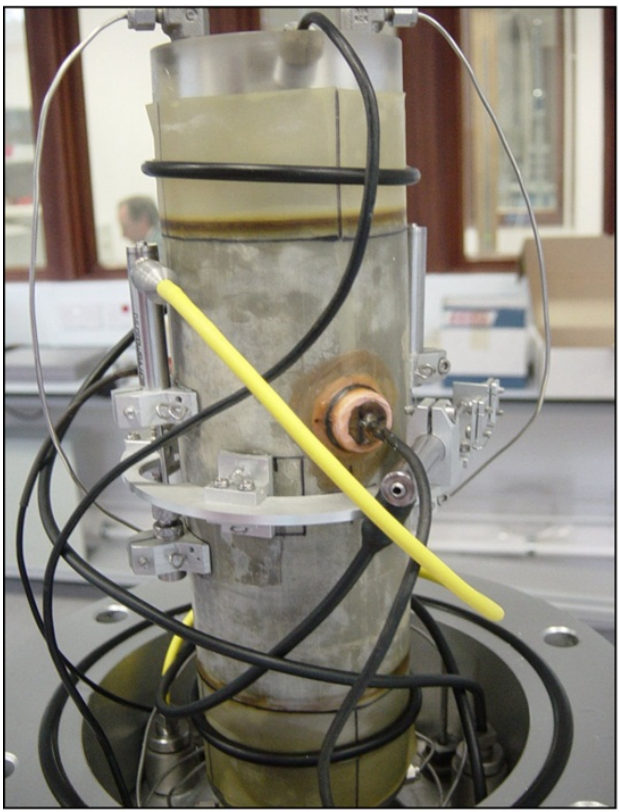

(a)

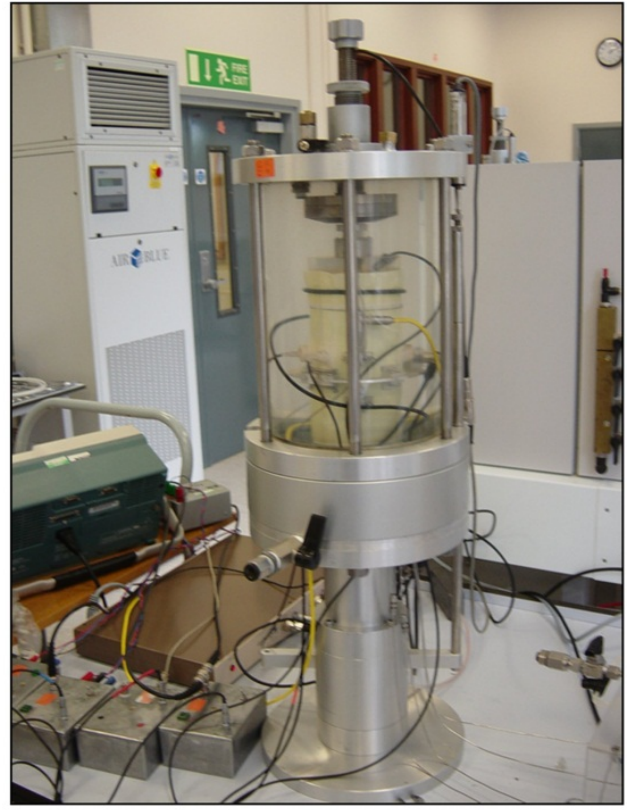

(b)

Figure 13. Modified stress path cell to incorporate vertical and horizontal bender system and local strain measuring system: (a) Installation of measuring devices, (b) triaxial stress path cell during testing (Sukolrat, 2007).

\section{Small-strain shear modulus based on bender element measurement}

According to elastic theory using the measured S-wave velocity $\left(\mathrm{V}_{\mathrm{s}}\right)$ and total mass density of the specimen $(\varrho=\gamma / g)$, the small-strain shear modulus $\left(\mathrm{G}_{\mathrm{o}}\right)$ can be calculated with the relationship $\mathrm{G}_{0}=\mathrm{Q} \cdot \mathrm{V}_{\mathrm{s}}{ }^{2}$. $\mathrm{G}_{\mathrm{o}}$ is an important and fundamental geomaterial property for a variety of geotechnical design applications and can be applied to all kinds of static (monotonic) and dynamic geotechnical problems at small strains (Richart et al. 1970, Jardine et al. 1986, Burland 1989). Note that the term "small-strain" is typically associated with the shear strain range below the elastic threshold strain $\left(10^{3}-10^{-2} \%\right)$. Within the small strain range where the deformations or strains are purely elastic and fully recoverable, the shear modulus is independent of strain amplitude and reaches a nearly constant limiting value of the maximum shear modulus. In this strain region, most geomaterials exhibit linear-elastic behavior.

A number of factors affecting Go have been extensively investigated and reported. These include the current state of the sample (e.g. stress state, overconsolidation ratio, density, void ratio, and microstructure), anisotropy, degree of saturation, aging, cementation, and temperature. Such factors can be briefly explained as the followings: 


\section{Current state}

The current state of a sample relative to Go is defined by: (i) existing normal stresses in the ground which is also known as the mean effective principle stress or confining pressure $\left(\sigma_{\mathrm{o}}{ }^{\prime}\right)$, (ii) the overconsolidation ratio (OCR), and (iii) the void ratio (e) or the density of the geomaterial (Q). By taking all parameters into account, a general expression as proposed by different investigators for Go of geomaterials is of the following form:

$$
G_{o}=A(O C R)^{k} f(e) p_{a}^{(1-n)}\left(\sigma_{o}^{\prime}\right)^{n}
$$

where $\mathrm{A}$ is a dimensionless material constant coefficient, $\mathrm{k}$ is a overconsolidation ratio exponent, $\mathrm{f}(\mathrm{e})$ is a void ratio function, $\mathrm{p}_{\mathrm{a}}$ is the reference stress or atmospheric pressure $(\sim 100$ $\mathrm{kPa}$ ) expressed in the same units as $\mathrm{G}_{0}$ and $\sigma_{\circ}{ }^{\prime}$, and $\mathrm{n}$ is a stress exponent. A number of studies have been conducted to estimate these parameters by relating with other physical geomaterial properties as summarized in Table 2 and Table 3.

\begin{tabular}{|c|c|c|c|}
\hline Parameter & Dependency & Typical value & References \\
\hline A & $\begin{array}{l}\text { Grain characteristics or } \\
\text { nature of grains, fabric or } \\
\text { microstructure of } \\
\text { geomaterial }\end{array}$ & $\begin{array}{l}\text { Determined by } \\
\text { regression analysis } \\
\text { for individual test }\end{array}$ & See Table 2 \\
\hline $\mathrm{k}$ & Plasticity index (PI) & $\begin{array}{l}\text { Vary from } 0 \text { to } 0.5 \\
\text { (for } \mathrm{PI}<40, \mathrm{k}=0 ; \\
\mathrm{PI}>40, \mathrm{k}=0.5 \text { ) }\end{array}$ & $\begin{array}{l}\text { Hardin and Black } \\
\text { (1968), Hardin and } \\
\text { Drnevich (1972) }\end{array}$ \\
\hline$f(e)$ & $\begin{array}{c}\text { Properties of packing and } \\
\text { density }\end{array}$ & See Table 3 & See Table 3 \\
\hline $\mathrm{N}$ & $\begin{array}{l}\text { Contact between particles } \\
\text { and strain amplitude }\end{array}$ & $\begin{array}{l}\text { Approximately } 0.5 \\
\text { at small strains }\end{array}$ & $\begin{array}{c}\text { Hardin and Richart } \\
\text { (1963), Hardin and } \\
\text { Black (1966, 1968), } \\
\text { Drnevich et al. (1967), } \\
\text { Seed and Idriss (1970), } \\
\text { Silver and Seed (1971), } \\
\text { Hardin and Drnevich } \\
\text { (1972), Kuribayashi et } \\
\text { al. (1975), Kokusho } \\
(1980)\end{array}$ \\
\hline
\end{tabular}

Table 2. Parameters describing a current state of sample for Go

$$
\mathrm{Go}_{\mathrm{o}}=\mathrm{A} \cdot \mathrm{f}(\mathrm{e}) \cdot\left(\sigma_{\mathrm{o}}{ }^{\prime}\right)^{\mathrm{n}}
$$




\begin{tabular}{|c|c|c|c|c|}
\hline Type of geomaterials & A & $\mathrm{f}(\mathrm{e})$ & $\mathrm{n}$ & References \\
\hline $\begin{array}{l}\text { Round-grained } \\
\text { Ottawa sand } \\
\text { Angular-grained } \\
\text { crushed quartz }\end{array}$ & 6,900 & $\begin{array}{l}(2.17-\mathrm{e})^{2} /(1+\mathrm{e}) \\
(2.97-\mathrm{e})^{2} /(1+\mathrm{e})\end{array}$ & 0.5 & Hardin and Black (1968) \\
\hline Clean sand & 41,600 & $0.67-e /(1+e)$ & 0.5 & $\begin{array}{c}\text { Shibata and Soelarno } \\
\text { (1975) }\end{array}$ \\
\hline Clean sand $\left(\mathrm{C}_{\mathrm{u}}<1.8\right)$ & 14,100 & $(2.17-\mathrm{e})^{2} /(1+\mathrm{e})$ & 0.4 & $\begin{array}{c}\text { Iwasaki and Tatsuoka } \\
\text { (1977) }\end{array}$ \\
\hline Clean sand & 9,000 & $(2.17-\mathrm{e})^{2} /(1+\mathrm{e})$ & 0.4 & Iwasaki et al. (1978) \\
\hline Toyoura sand & 8,400 & $(2.17-\mathrm{e})^{2} /(1+\mathrm{e})$ & 0.5 & Kokusho (1980) \\
\hline Clean sand & 7,000 & $(2.17-\mathrm{e})^{2} /(1+\mathrm{e})$ & 0.5 & Yu and Richart (1984) \\
\hline Ticino sand & 7,100 & $(2.27-e)^{2} /(1+e)$ & 0.4 & Lo Presti et al. (1993) \\
\hline Clean sand & 9,300 & $1 / \mathrm{e}^{1.3}$ & 0.45 & Lo Presti et al. (1997) \\
\hline $\begin{array}{c}\text { Reconstituted NC Kaolinite } \\
(P I=20) \text { and undisturbed } \\
\text { NC clays }\end{array}$ & 3,270 & $(2.97-e)^{2} /(1+e)$ & 0.5 & Hardin and Black (1968) \\
\hline $\begin{array}{l}\text { Reconstituted NC Kaolinite } \\
\text { (PI }=35) \\
\text { Reconstituted NC Bentonite } \\
(\mathrm{PI}=60)\end{array}$ & 4,500 & $\begin{array}{l}(2.97-\mathrm{e})^{2} /(1+\mathrm{e}) \\
(4.4-\mathrm{e})^{2} /(1+\mathrm{e})\end{array}$ & $\begin{array}{l}0.5 \\
0.5\end{array}$ & $\begin{array}{l}\text { Marcuson and Wahls } \\
\qquad(1972)\end{array}$ \\
\hline Remolded clay $(\mathrm{PI}=0 \sim 50)$ & $2,000 \sim 4,000$ & $(2.97-e)^{2} /(1+e)$ & 0.5 & Zen et al. (1978) \\
\hline $\begin{array}{l}\text { Undisturbed NC clay } \\
\qquad(\mathrm{PI}=40 \sim 85)\end{array}$ & 90 & $(7.32-\mathrm{e})^{2} /(1+\mathrm{e})$ & 0.6 & Kokusho et al. (1982) \\
\hline Clay deposits (PI = 20 150) & 5,000 & $1 / \mathrm{e}^{1.5}$ & 0.5 & $\begin{array}{l}\text { Shibuya and Tanaka } \\
(1996)^{\dagger}\end{array}$ \\
\hline Remolded clay (PI = 20 60) & 24,000 & $1 /(1+e)^{2.4}$ & 0.5 & Shibuya et al. (1997) ${ }^{\dagger}$ \\
\hline Sand and clay & 6,250 & $1 /\left(0.3+0.7 \mathrm{e}^{2}\right)$ & 0.5 & Hardin (1978) \\
\hline Several soils & 5,700 & $1 / \mathrm{e}$ & 0.5 & Biarez and Hicher (1994) \\
\hline
\end{tabular}

Note: $\mathrm{Go}_{\mathrm{o}}$ and $\sigma_{\mathrm{o}}{ }^{\prime}$ are in $\mathrm{kPa},{ }^{+}$using effective vertical stress $\left(\sigma_{\mathrm{v}}{ }^{\prime}\right)$ instead of $\sigma_{\mathrm{o}}{ }^{\prime}, \mathrm{Cu}=$ Coefficient of Uniformity

Table 3. Function and constants in proposed empirical equations on $\mathrm{G}_{0}$

\section{Anisotropy}

Anisotropic Go of geomaterials is generally described in terms of stress-induced anisotropy and inherent anisotropy (Stokoe et al. 1985).The stress-induced anisotropy results from the anisotropy of the current stress condition and is independent of the stress and strain history of the geomaterial. The inherent or fabric anisotropy results from structure or fabric of the geomaterial that reflects the deposition or forming process (e.g. aging, cementation). Both stress-induced anisotropy and fabric anisotropy of Go depend on the direction of loading (Mitchell and Soga 2005). Such fabric anisotropy of Go can be evaluated based on S-wave measurements using bender elements (Sawangsuriya et al. 2007b). For example, Go is a 
function of the principal effective stresses in the directions of wave propagation and particle motion and is independent of the out-of-plane principal stress (Stokoe et al. 1995). The inherent anisotropy can be evaluated by measuring body wave velocities propagating through the specimen subjected to isotropic states of stress (i.e., mean effective stress). For the stress-induced anisotropy, the measurements are taken from specimen subjected to anisotropy states of stress (i.e., changes in vertical stress while maintaining average principal stresses).

Under anisotropic states of stress, the representative stiffness values can be different, depending on the measurement conditions and the sample preparation procedures. The anisotropy of the stress state induces anisotropy of small-strain stiffness. An empirical equation for Go under anisotropic stress condition is expressed as (Roesler 1979, Stokoe et al. 1985):

$$
G_{o}=A(O C R)^{k} F(e) p_{a}^{1-n} \sigma_{i}^{\prime n_{i}} \sigma_{j}^{n_{j}}
$$

where $\sigma_{i}^{\prime}$ is the effective normal stress in the direction of wave propagation, $\sigma_{j}^{\prime}$ is the effective normal stress in the direction of particle motion, and $n=n_{i}+n_{j}$.

\section{Degree of saturation}

Early studies on the influence of the degree of saturation on Go described a coupled motion of the solid particles and the fluid (Biot 1956, Hardin and Richart 1963, Richart et al. 1970). According to Biot's theory, no structural coupling exists between the solid particle and the fluid (the fluid has no shearing stiffness), the coupling in the shearing mode is only developed by the relative motions of the solid and fluid as indicated by the term involving the apparent additional mass density and thus Go can be expressed as:

$$
G_{o}=v_{s}^{2}\left(\rho+\frac{\rho_{f} \rho_{a}}{\rho_{f}+\rho_{a}}\right)
$$

where $\varrho$ is the mass density of the solid particles, @f is the mass density of fluid, and @a is the mass density of an additional apparent mass. In a real geomaterial, @a varies with the grain size and permeability; however, the total mass density of the saturated geomaterial could be substituted into the mass density term of Eq. (10) to take into account the coupling effect of the mass of the fluid. The shear wave velocity of saturated geomaterial is therefore less than that of dry geomaterial because the added apparent mass of water moving along with the geomaterial skeleton (i.e., the drag of the water in the pores). Recent studies by Santamarina et al. (2001) and Inci et al. (2003) indicated that the response of Go by varying the degree of saturation demonstrates three phases of behavior and is attributed to contact-level capillary forces or suction. A sharp increase in Go is observed at the beginning of the drying process, followed by a period of gradual increase in measured $G_{0}$, and a final sharp increase in Go at the end of the drying period. 


\section{Aging}

A time-dependent nature of Go of geomaterials has been reported by several investigators (Afifi and Woods 1971, Marcuson and Wahls 1972, Afifi and Richart 1973, Stokoe and Richart 1973, Trudeau et al. 1974, Anderson and Woods 1975, Anderson and Woods 1976, Anderson and Stokoe 1978, Isenhower and Stokoe 1981, Athanasopoulos 1981, Kokusho 1987). Results of these investigations indicate that Go tends to increase with the duration of time under a constant confining pressure after the primary consolidation is complete due to a time effect results from strengthening of particle bonding. The time dependency of Go increase can be characterized by two phases: (i) an initial phase due to primary consolidation and (ii) a second phase in which Go increases about linearly with the logarithm of time and occurs after completion of primary consolidation, also referred as the long-term time effect (Fig. 14). The second phase of secondary consolidation occurs after primary phase when Go increases continuously with time. The rate of secondary increase in Go is related to thixotropic changes in the clay structure and is determined to be linear when plotted versus the logarithm of time. To incorporate this long-term time effect, the change in Go with time can be expressed by:

$$
\Delta G=N_{G} G_{1000}
$$

and

$$
N_{G}=\left(\frac{1}{G_{1000}}\right)\left(\frac{\Delta G}{\log _{10}\left(t_{2} / t_{1}\right)}\right)
$$

where $\Delta G$ is the increase in Go over one logarithm cycle of time, $\mathrm{G}_{1000}$ is the value of Go measured after 1,000 minutes of application of constant confining pressure following the primary consolidation, and $\mathrm{N}_{\mathrm{G}}$ is the aging increment coefficient, which indicates an increase of Go within one logarithmic cycle of time.

The duration of primary consolidation and the magnitude of the secondary increase, as defined by change in Go per logarithmic cycle of time, vary with geomaterial types and stress conditions (i.e., confining pressure). For sands, the rate of increase in Go is relatively small ( 1 to $3 \%$ per log cycle of time) but for clays the effect is quite remarkable as illustrated in Fig. 15.

\section{Cementation}

Cementation occurs either naturally due to the precipitation or formation of salts, calcite, alumina, iron oxides, silicates, and aluminates or artificial stabilization processes produced by adding lime, cement, asphalt, fly ash, or other bonding agents to geomaterials. The effect of cementation on Go have been evaluated by Clough et al. (1981), Acar and El-Tahir (1986), Saxena et al. (1988), Lade and Overton (1989), Baig et al. (1997), Fernandez and Santamarina (2001), Yun and Santamarina (2005). Go of cemented materials increases with increasing cement content and confining pressure (Fig. 16). Additionally at low confinement, the 
stiffness behavior of cemented materials is controlled by the cementation and the materials become brittle, whereas at high confinement the behavior is controlled by the state of stress and resembles an uncemented material, which becomes more ductile.

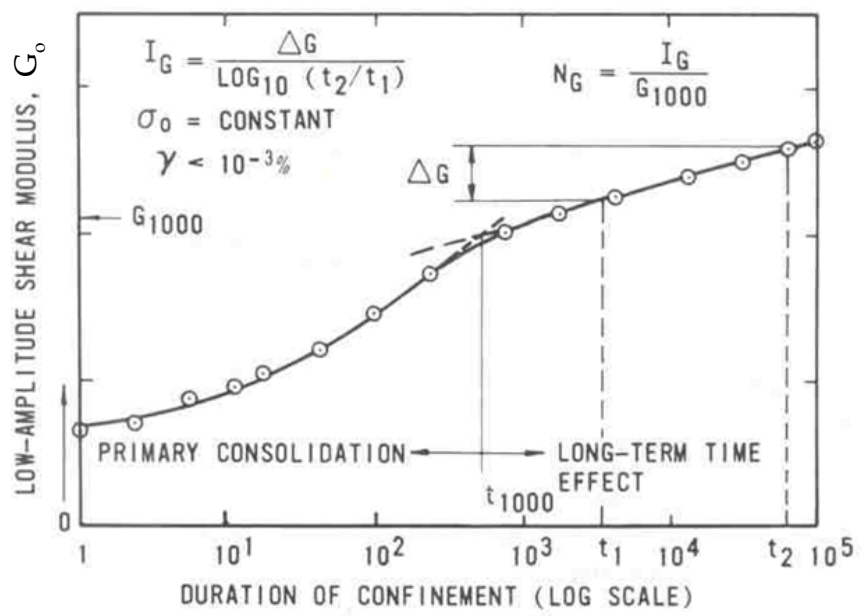

Figure 14. Phases of Go versus confinement time (Anderson and Stokoe 1978).

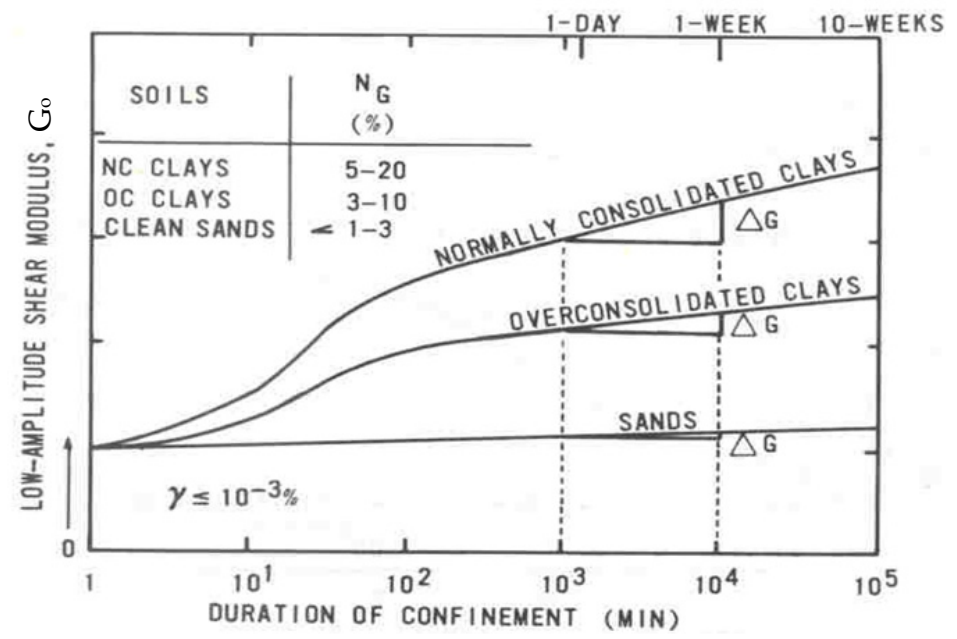

Figure 15. Effect of aging on Go (Anderson and Stokoe 1978). 


\section{Temperature}

Effect of temperature on time-dependent changes in Go was reported in Bosscher and Nelson (1987), Fam et al. (1998). The dependency of Go on temperature suggests that higher temperatures cause the stiffness increase with time. Fam et al. (1998) presented the evolution in velocity with time for coarse-grained granular salt specimen under a constant effective stress and subjected to a temperature step (heating-cooling cycle) as illustrated in Fig. 17. The rate of increase in velocity with time increases at higher temperatures (Fam et al. 1998). Bosscher and Nelson (1987) studied Go of frozen Ottawa 20-30 sand as a function of the confining pressure, the degree of ice saturation, the relative density, and the temperature. They found that Go of frozen sand is higher than that of non-frozen state. At temperatures near the melting point of ice, Go can be significantly influenced by the confining pressure, the degree of ice saturation, and the relative density (Bosscher and Nelson 1987).

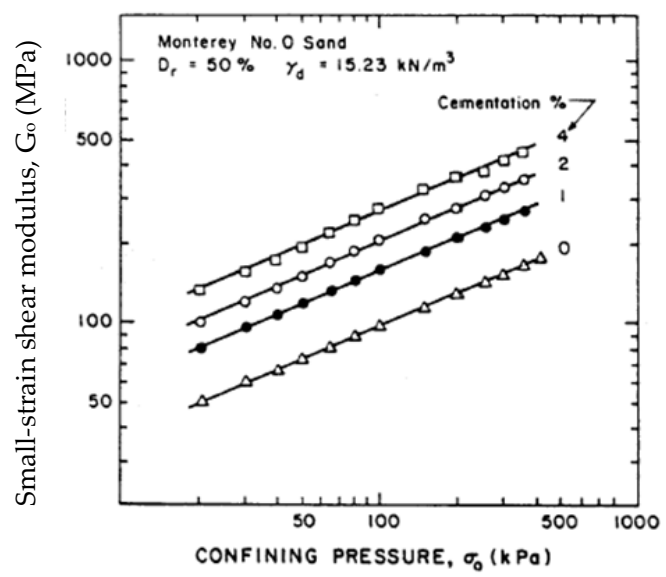

Figure 16. Effect of cementation on Go (Acar and El-Tahir 1986).

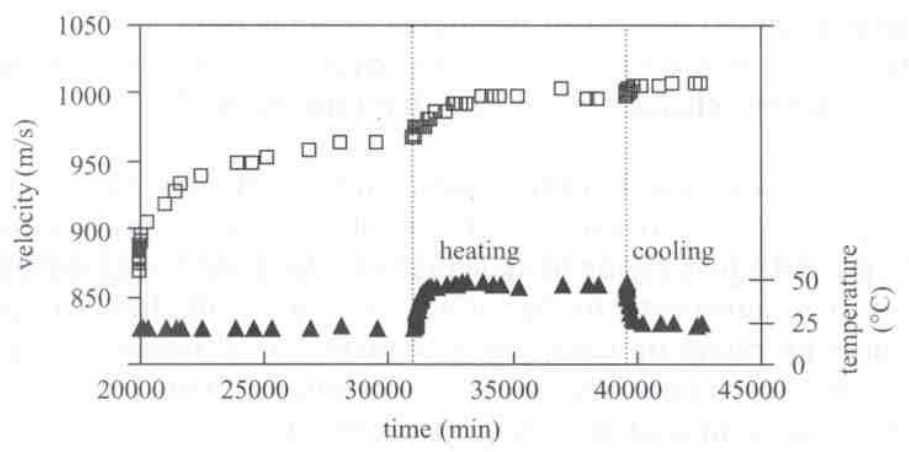

Figure 17. Effect of temperature on time-dependent changes in velocity for a coarse-grained granular salt specimen under a constant vertical load (Fam et al. 1998). 


\section{Application of wave propagation methods in geoengineering quality control process}

The quality of the engineered earth fills depends on the suitability and compaction of the materials used. Earthwork compaction acceptance criteria are typically based on adequate dry density of the placed earthen materials achieved through proper moisture content and compaction energy. For instance, compaction specifications often require achievement of an in-situ dry density of $90-95 \%$ of the maximum value obtained from laboratory standard or modified Proctor test. According to this approach, by achieving a certain dry density using an acceptable level of compaction energy assures attainment of an optimum available level of structural properties and also minimises the available pore space and thus future moisture changes.

The question of the achieved structural property, which is the ultimate objective quality control, however remains unfulfilled. Dry density is only a quality index used to judge compaction acceptability and is not the design parameter or relevant property for engineering purposes. For compacted highway, railroad, airfield, parking lot, and mat foundation subgrades and support fills, the ultimate engineering parameter of interest is often the shear modulus of geomaterials, which is a direct structural property for determining load support capacity and deformation characteristic in engineering design.

Shear modulus of compacted geomaterials depends on density and moisture but also on fabric and texture of geomaterials, which varies along the roadway route. The conventional approach of moisture-density control, however, does not reflect the variability of the texture and microstructure of geomaterials and thus their shear modulus. Even if the structural layers satisfy a compaction quality control requirement based on density testing, a large variability in shear modulus can still be observed (Sargand et al. 2000; Nazarian and Yuan, 2000). Additionally, the comparison between density and modulus tests suggests that conventional density testing cannot be used to define subtle changes in the stiffness of the compacted earth fills (Fiedler et al. 1998). Shear modulus is a more sensitive measure of the texture and fabric uniformity than density. The stiffness non-uniformity is directly related to progressive failures and life-cycle cost, direct stiffness testing which can be conducted independently and in conjunction with conventional moisture-density testing is anticipated to reduce variability and substantially enhance quality control of the earthwork construction.

Ismail and Rammah (2006) proposed a test setup and procedure by which the small-strain shear modulus can be measured accurately by propagating elastic shear wave through the compacted geomaterial during laboratory compaction test. They designed a test setup in such a way that it can be readily incorporated into the conventional compaction mould as shown in Fig. 18. In addition, their procedures can be adopted in compaction works e.g. road construction, embankments, and earth structures. Consequently, incorporating the shear modulus into laboratory compaction tests, will guarantee fulfilment of the design criteria in term of dry density-moisture-modulus relationship. 


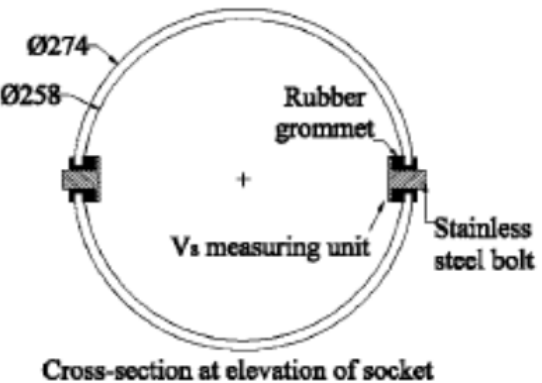

Dim. in $\mathrm{mm}$

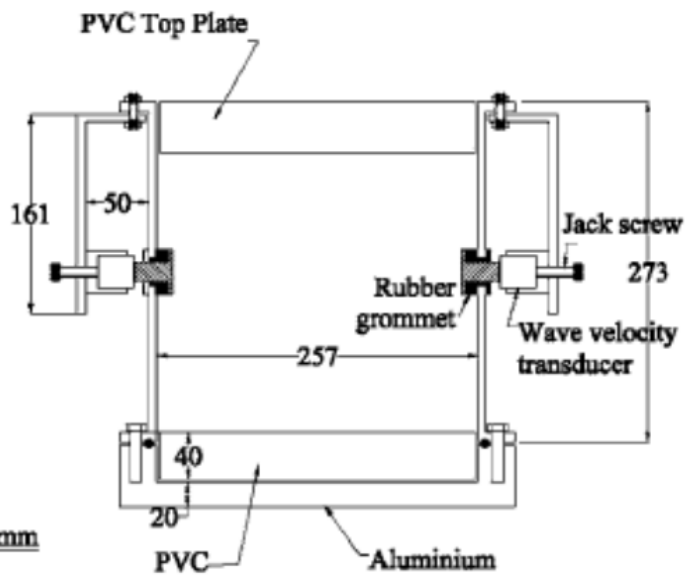

Sectional Elevation

Figure 18. Seismic compaction mold (Ismail and Rammah 2006).

Sawangsuriya et al. (2008a) presented the experimental investigation of the shear modulusmatric suction-moisture content-dry unit weight relationship using three compacted subgrade soils. Compacted specimens were prepared over a range of molding water contents from dry to wet of optimum using enhanced, standard, and reduced Proctor efforts. A S-wave propagation technique known as bender elements was utilized to assess the shear wave velocity and corresponding Go of the compacted specimens. S-wave traces of the clayey sand compacted with enhanced Proctor, standard Proctor, and reduced Proctor efforts are shown in Fig. 19. S-wave traces of the silt and lean clay compacted with standard Proctor effort are shown in Fig. 20.
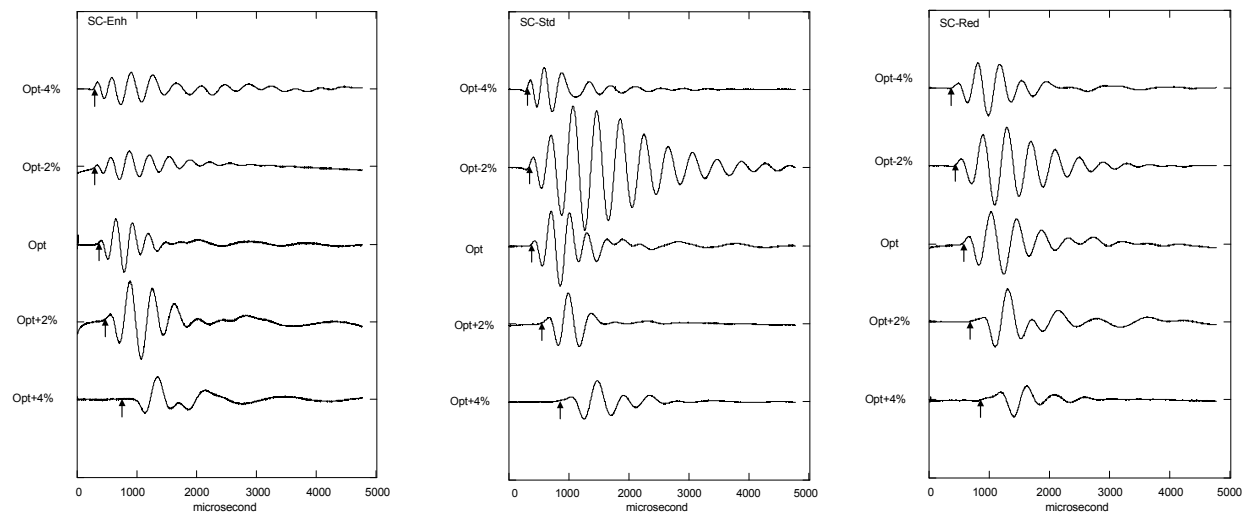

Figure 19. S-wave traces of the clayey sand compacted with enhanced Proctor (a), standard Proctor (b), and reduced Proctor (c) efforts (Sawangsuriya et al. 2008a). 

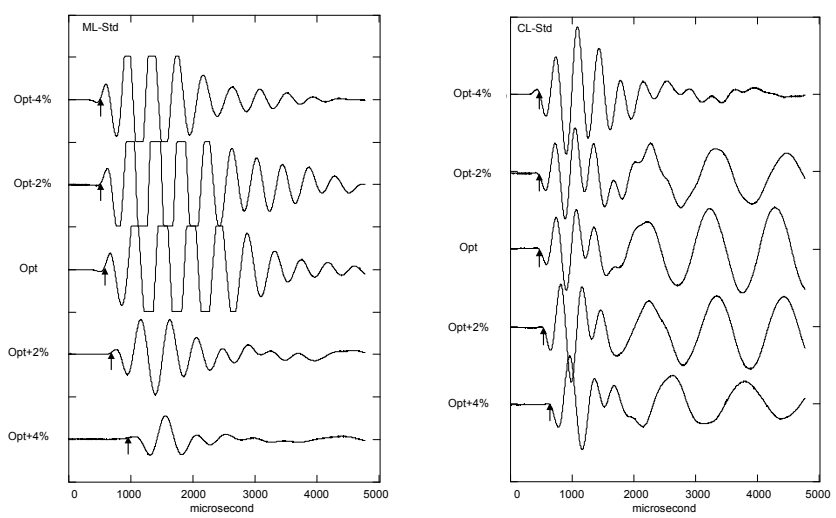

Figure 20. S-wave traces of the silt and lean clay compacted with standard Proctor effort (Sawangsuriya et al. 2008a).

\section{Application of wave propagation methods for ground monitoring}

In the past 20 years, the use of wave propagation methods (e.g. seismic. etc.) seismic reflection and refraction, seismic down-hole, up-hole and cross-hole etc. for ground monitoring has been promoted intensively because it is non-destructive and is conducted under in situ condition. The wave propagation methods are commonly used to determine stiffness-depth profile. Typically, the wave propagation methods can be classified into subsurface and near-surface methods as schematised in Fig. 21.

The subsurface methods including seismic down-hole, seismic up-hole, and seismic crosshole are normally employed to monitor ground stiffness when the depth of interest is greater than 15 meters (Hooker 1998). In these methods, one or more boreholes are usually required in order that the source and/or the receiver can be installed. While the seismic cone penetration test can provide both stiffness and strength properties of the geomaterials during its penetration. The disadvantage of the subsurface method is that the cost of measurement is relatively high due to the cost of borehole casting. An alternative method is the near-surface method which provides simpler and more cost-effective approaches. The near-surface method is performed on the basis of the ability of wave propagation through the ground strata. When waves propagate through soil layers having different properties, they refract and/or reflect at different time. Once the arrival time is known, wave velocities and stiffness of each layer can be determined.

With the near-surface method, the Spectral Analysis of Surface Waves (SASW) using surface waves is another technique that can monitor both ground stiffness at shallow depth and layer thicknesses of subsurface profiles. The surface wave method utilises the dispersive characteristic of Rayleigh waves, which are elastic waves that propagate along the ground surface. Surface (Rayleigh) wave velocity varied with frequency is measured by utilizing the dispersion characteristics of surface wave and the fact that surface waves propagate to 
depths that are proportional to their wavelengths or frequencies in order to determine the stiffness of subsurface profiles. The objective in SASW testing is to make field measurements of surface wave dispersion (i.e., measurements of surface wave velocity at various wavelengths) and to determine the shear wave velocities of the layers in the profile based on the fact that surface waves propagate to depths that are proportional to their wavelengths (Mayne et al. 2001).

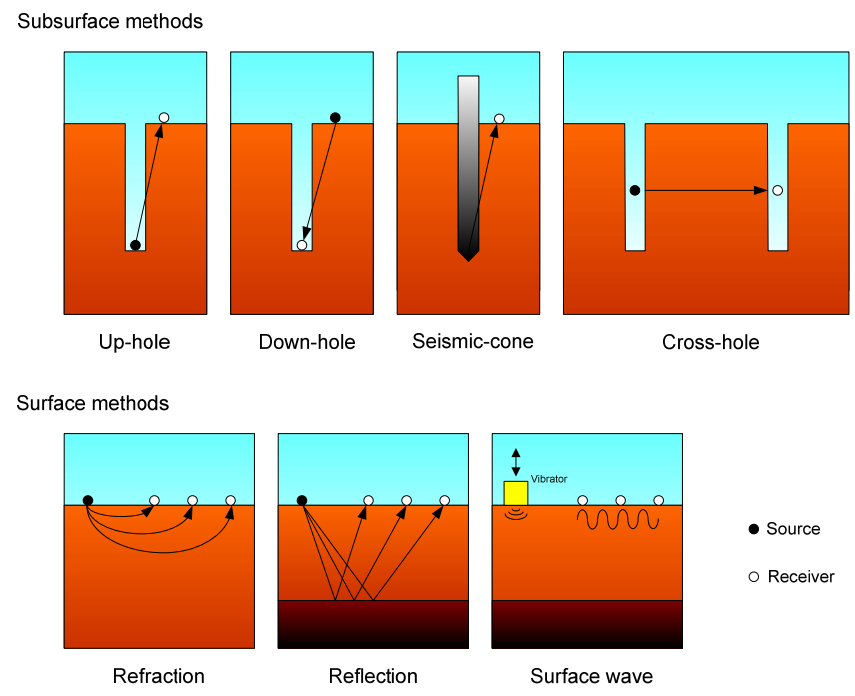

Figure 21. Wave propagation methods in ground monitoring (Sawangsuriya et al. 2008c).

The seismic methods have been employed to monitor ground improvement such as dynamic compaction and vibrofloatation methods (Hooker 1998). The measurement was made at the site before and after the ground improvement to establish stiffness profile in order that the performance of ground improvement can be monitored. Moreover, in some ground treatments e.g. grouted backfill and stone column, the near-surface wave propagating method can be employed to monitor their performance (Cuellar 1997).

Since ground moisture is sensitive to rise in water table, infiltration, and evaporation. Changes in ground moisture and hence in its modulus can occur over the service life of an engineered structure irrespective of the initial moisture conditions imposed during construction. The variation in ground modulus with moisture should be monitored systematically to reflect mechanical behavior of compacted engineered structures after construction (i.e., during postcompaction state). The influences of ground moisture should be also considered in performance assessment in such a way that the anticipated in-service conditions are taken into account. Sawangsuriya et al. (2009b) developed a laboratory method for identifying and examining the variation of modulus with moisture and suction in order to improve the ground performance assessment. Their study evaluated the Go of compacted specimens using bender elements under the suction and moisture variation in the laboratory as shown in Fig. 22. Such method allows monitoring the modulus change with respect to the suction and moisture on 
the same specimen without disturbance. Fig. 23 illustrates shear wave time series during desaturation of lean clay specimen compacted near optimum.

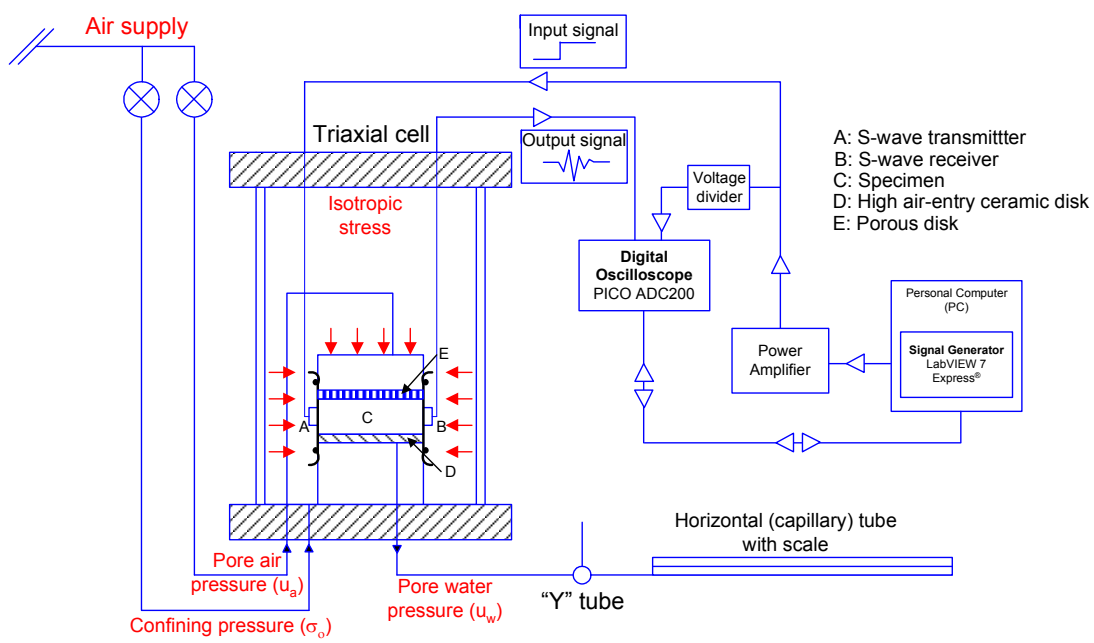

Figure 22. Schematic diagram of Go test using bender elements under the suction and moisture variation (Sawangsuriya et al. 2009b).

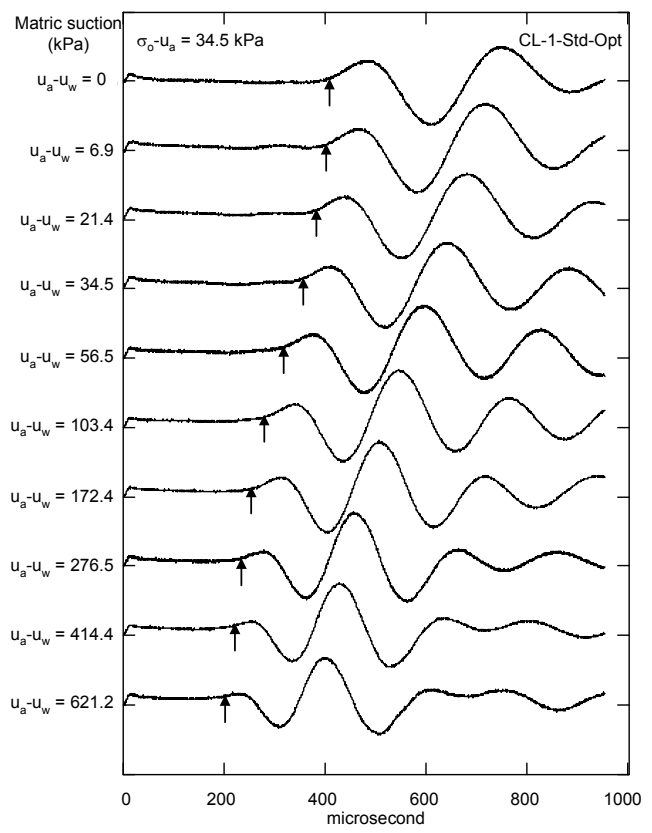

Figure 23. Shear wave time series during desaturation of lean clay specimen compacted near optimum (Sawangsuriya et al. 2009b). 


\section{Application of wave propagation methods in pavement design and analysis}

The new AASHTO 2002 highway design relies heavily on mechanistic pavement properties. Current mechanistic-empirical design procedures for structural design of flexible pavements consider the mechanical properties of pavement material such as stiffness and strength. Several countries are currently either implementing or favoring the development of performance-based specifications. To successfully implement a mechanistic-empirical design procedure and to move toward performance-based specifications, a cost-effective, reliable, and practical means to assess the stiffness and strength of highway materials is necessary since both stiffness and strength of pavement layers plays a key role on the overall quality and performance of pavements.

One of the potential approaches to directly assess stiffness of geomaterials both in the laboratory and in the field is to employ Go tests. Generally, Go of geomaterials is routinely measured in earthquake engineering. In highway engineering, the application of Go tests to assess the stiffness of highway materials and structural variability for pavement performance has increased dramatically (Kim and Stokoe 1992, Souto et al. 1994, Kim et al. 1997, Chen et al. 1999, Nazarian et al. 1999, Fiedler et al. 2000, Yesiller et al. 2000, Zeng et al. 2002, Nazarian et al. 2003). The key advantage of Go tests over conventional modulus tests is their ability to rapidly and non-destructively assess the shear modulus of highway materials at the surface or under a free-field condition (i.e., zero confining pressure). Laboratory test methods are also available for Go tests that can reproduce similar results to those measured in the field. Moreover in the field, the modulus changes in response to temporal variations in moisture content. The modulus changes in response to changes in moisture can be simply incorporated in Go test in order to provide a model to estimate changes in modulus due to changes in moisture content for the pavement design and analysis. The relationship can be quantified empirically using a modulus ratio defined as the ratio of $G_{0}$ at a specified moisture equilibrium to Go at optimum compaction conditions. An example of modulus ratio is plotted against the degree of saturation for types of geomaterials as illustrated in Fig. 24.

Typically, the associated strain levels corresponding to many proposed geotechnical engineering structures such as foundations, retaining walls, tunnels, and pavements are however much larger (Mair 1993, Sawangsuriya et al. 2005). For example, the strain levels of the bender element are below $5 \times 10^{-3} \%$, whereas the strain levels of the resilient modulus commonly used in the design of flexible pavement structures ranges from 0.01 to $0.1 \%$ (Sawangsuriya et al. 2005). In order to correct the small-strain modulus measurements to such relevant levels of strain amplitude imposed by the proposed structure, the modulusstrain relationship, or called strain-dependent modulus degradation curve, can be employed for a given operating stress level and soil type.

For pavement bases, subbases and subgrades, the stress-strain behaviour of soil is highly nonlinear and soil modulus may decay with strain by orders of magnitude. A relationship between the small-strain modulus (strains less than $10^{-2} \%$ ) and non-linear behaviour 
exhibited by soils at large strains (above $10^{-2} \%$ ) must be established. Generally, strains in base and subbase courses vary from 0.01 to $1 \%$, whereas those in subgrades may vary from 0.003 to $0.6 \%$ (see Fig. 1). Therefore, the pavement base, subbase, and subgrade layers involve strains at higher levels, i.e., typical strain range of $10^{-2}$ to $1 \%$, and soil exhibits nonlinear properties. Fig. 1 also shows that the resilient modulus $\left(\mathrm{M}_{\mathrm{R}}\right)$ test operates within these strain range. However, the decay curve of measured soil moduli from the small-strain tests must be evaluated and corrected to the modulus corresponding to these strain levels.

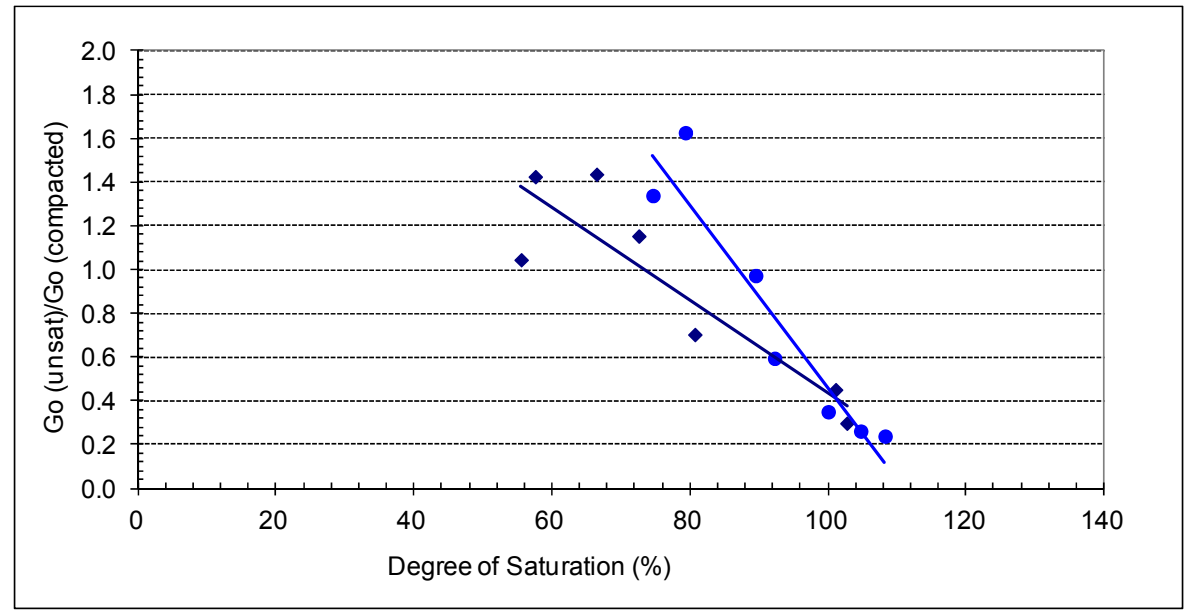

Figure 24. Go at a specified moisture equilibrium normalized with Go at optimum compaction condition vs. degree of saturation (Gupta et al. 2007).

\section{Summary}

Stiffness of geomaterials is an important engineering property, commonly used in geomechanical design and analysis. The deformation performance of geomaterials used to support engineered structures depends primarily on their stiffness. Therefore, it is important that the laboratory and field investigation should be performed to identify and classify geomaterials as well as to assess their mechanical properties for the engineering design and analysis. This chapter summarizes the wave propagation methods that permit the determination of the stiffness of the geomaterials. By knowing the elastic wave velocities as measured with the wave propagation method and total mass density of the medium, the corresponding stiffness of the geomaterials can be determined. One of the wave propagation methods based on the S-wave measurement is called a bender element test. It is a rapid, non-destructive, and low cost method, which can provide a realistic engineering design parameter (e.g. shear modulus). Moreover, elastic waves permit monitoring the elastic (stiffness) and inertial (mass density) properties of geomaterials while evaluating other coupled processes, i.e., the changes in state of effective stresses, the stress-induced anisotropy, the generation of geo-structure in soft sediments, etc. 
The use of bender elements to generate and receive shear waves in geomaterials has become a very robust technique in geoengineering design and analysis and has been widely adopted for determining and monitoring stiffness of geomaterials both in the laboratory and field. However as with any other wave propagation techniques, the interpretation of bender element-collected data is controlled by wave characteristics, boundary conditions, and properties of the medium. Guidelines for designing test geometries and interpretation measured data from the wave propagation experiments are summarized herein. A bender element test has been employed for a variety of geoengineering applications, i.e., the mechanistic based design development, the long-term performance monitoring as well as quality control process during construction.

\section{Author details}

Auckpath Sawangsuriya

Bureau of Road Research and Development

Department of Highways, Thailand

\section{References}

Acar, Y. B. and EL-Tahir, E. A. (1986), “Low Strain Dynamic Properties of Artificially Cemented Sand," Journal of Geotechnical Engineering, ASCE, Vol. 112, No. 11, pp. 10011015.

Afifi, S. S. and Richart, F. E., Jr. (1973), "Stress-History Effects on Shear Modulus of Soils," Soils and Foundations, Vol. 13, No. 1, pp. 77-95.

Afifi, S. S. and Woods, R. D. (1971), "Long-Term Pressure Effects on Shear Modulus of Soils," Journal of the Soil Mechanics and Foundations Division, ASCE, Vol. 97, No. SM10, pp. 1445-1460.

Anderson, D. G. and Stokoe, K. H., II (1978), "Shear Modulus: A Time-Dependent Soil Property," Dynamic Geotechnical Testing, ASTM STP 654, Philadelphia, PA, pp. 66-90.

Anderson, D. G. and Woods, R. D. (1975), "Comparison of Field and Laboratory Shear Moduli," Proceedings of the Conference on In Situ Measurement of Soil Properties, Raleigh, NC, Vol. 1, pp. 69-92.

Anderson, D. G. and Woods, R. D. (1976), "Time-Dependent Increase in Shear Modulus of Clay," Journal of the Geotechnical Engineering Division, ASCE, Vol. 102, No. GT5, pp. 525537.

Arroyo, M., Wood, D.M., Greening, P.D., Medina, L., and Rio, J. (2006). “Effect of sample size on bender-based axial Go measurements" Geotechnique, Vol.56, No.1, 39-52.

Athanasopoulos, G. A. (1981), “Time Effects on Low-Amplitude Shear Modulus of Cohesive Soils," Report UMEE 81R1, The University of Michigan, MI.

Atkinson, J. H. (2000), “Non-Linear Soil Stiffness in Routine Design," Geotechnique, 40 Rankine Lecture, pp. 487-508. 
Atkinson, J. H. and Sallfors, G. (1991). “Experimental determination of stress-strain-time characteristics in laboratory and in situ tests" Proceedings of the 10th European Conference on Soil Mechanics and Foundation Engineering, Florence, Italy, 915-956.

Baig, S., Picornell, M., and Nazarian, S. (1997), "Low Strain Shear Moduli of Cemented Sands," Journal of Geotechnical Engineering, ASCE, Vol. 123, pp. 540-545.

Baldi, G., Bruzzi, D., and Superbo, S. (1988), "Seismic Cone in Po River Sand," Proceedings of the $1^{\text {st }}$ International Symposium on Penetration Testing, Balkema, Vol. 1, pp. 643-650.

Biarez, J. and Hicher, P.-Y. (1994), Elementary Mechanics of Soil Behaviour-Saturated Remoulded Soils, Balkema.

Biot, M. A. (1956), "Theory of Propagation of Elastic Waves in a Fluid-Saturated Porous Solid," Journal of the Acoustic Society of America, Vol. 28, No. 2, pp. 168-191.

Bolton, M. D. and Wilson, J. M. R. (1989), “An Experimental and Theoretical Comparison between Static and Dynamic Torsional Soil Tests," Geotechnique, Vol. 39, No. 4, pp. 585599.

Bosscher, P. J. and Nelson, D. L. (1987), “Resonant Column Testing of Frozen Ottawa Sand," Geotechnical Testing Journal, ASTM, Vol. 10, No. 3, pp. 123-134.

Brignoli, E. G. M, Gotti, M. and Stokoe, K. H. (1996). “Measurement of shear waves in laboratory specimens by means of piezoelectric transducers" Geotechnical Testing Journal, Vol.19, No.4, 384-397.

Burland, J. B. (1989), “The Ninth Lauritis Bjerrum Memorial Lecture: 'Small is Beautiful'- the Stiffness of Soils at Small Strains," Canadian Geotechnical Journal, Vol. 26, pp. 499-516.

Campanella, R. G. (1994), "Field Methods for Dynamic Geotechnical Testing: An Overview of Capabilities and Needs," Dynamic Geotechnical Testing II, ASTM STP 1213, Philadelphia, PA, pp. 3-23.

Campanella, R. G., Robertson, P. K., and Gillespie (1986), "Seismic Cone Penetration Test," Proceedings of Sessions on In Situ 86, ASCE Specialty Conference on Use of In Situ Tests in Geotechnical Engineering, Blackburg, VA, pp. 116-130.

Cascante, G., Santamarina, J. C., and Yassir, N., (1998), "Flexural Excitation in a Standard Resonant Column Device," Canadian Geotechnical Journal, Vol. 35, No. 3, pp. 488-490.

Chang, C. S., Misra, A., and Sundaram, S. S. (1991), "Properties of Granular Packings under Low Amplitude Cyclic Loading," Soil Dynamics and Earthquake Engineering, Vol. 10, No. 4, pp. 201-211.

Chen, D.-H., Wu, W., He, R., Bilyeu, J., and Arrelano, M. (1999), “Evaluation of In-Situ Resilient Modulus Testing Techniques," Recent Advances in the Characterization of Transportation Geo-Materials, Geotechnical Special Publication, No. 86, ASCE, Reston, VA., pp. 1-11.

Cho, G. C. and Santamarina, J. C. (2001), “Unsaturated Particulate Materials-Particle-Level Studies," Journal of Geotechnical and Geoenvironmental Engineering, ASCE, Vol. 127, No. 1, pp. 84-96.

Clough, G. W., Sitar, N., Bachus, R. C., and Rad, N. S. (1981), “Cemented Sands under Static Loading," Journal of the Geotechnical Engineering Division, ASCE, Vol. 107, pp. 799-817. 
Dobry, R. (1989), "Some Basic Aspects of Soil Liquefaction during Earthquakes," Earthquake Hazards and the Design of Constructed Facilities in the Eastern United States, Annual of the New York Academy of Sciences, No. 558, pp. 172-182.

Drnevich, V. P. (1977), "The Resonant Column Test," Report to the U.S. Army Corps of Engineers, Soil Mechanics Series, No. 23, Department of Civil Engineering, The University of Kentucky.

Drnevich, V. P. (1985), "Recent Developments in Resonant Column Testing," Richart Commemorative Lectures, Proceedings of the ASCE Specialty Session, Detroit, MI, pp. 79-107.

Drnevich, V. P., Hall, J. R., and Richart, F. E. (1967), "Effects of Amplitude of Vibration on the Shear Modulus of Sand," Proceedings of the International Symposium on Wave Propagation and Dynamic Properties of Earth Materials, Albuquerque, NM, pp. 189-199.

Drnevich, V. P., Hardin, B. O., and Shippy, D. J. (1978), “Modulus and Damping of Soils by the Resonant-Column Method," Dynamic Geotechnical Testing, ASTM STP 654, Philadelphia, PA, pp. 91-125.

Duffy, J. and Mindlin, R. D. (1957), "Stress-Strain Relations of a Granular Medium," Journal of the Applied Mechanics, Vol. 24, No. 4, pp. 585-593.

Dyvik, R. and Madshus, C. (1985), "Lab Measurements of Gmax Using Bender Elements," Proceedings of the Geotechnical Engineering Division: Advances in the Art of Testing Soil Under Cyclic Conditions, ASCE, Detroit, MI, pp. 186-196.

Edil, T. B. and Luh, G.-F. (1978), "Dynamic Modulus and Damping Relationships for Sands," Proceedings on the Specialty Conference on Earthquake Engineering and Soil Dynamics, ASCE, Pasadena, CA, pp. 394-409.

Fam, M. and Santamarina, J. C. (1995), "Study of Geoprocesses with Complementary Wave Measurements in an Oedometer," Geotechnical Testing Journal, ASTM, Vol. 18, No. 3, pp. 307-314.

Fam, M., Santamarina, J. C., and Dusseault, M. (1998), “Wave-Based Monitoring Processes in Granular Salt," Journal of the Environmental and Engineering Geophysics, Vol. 3, pp. 15-26.

Fernandez, A. and Santamarina, J. C. (2001), "Effect of Cementation on the Small-Strain Parameters of Sands," Canadian Geotechnical Journal, Vol. 38, No. 1, pp. 191-199.

Fiedler, S. A., Main, M., and DiMillio, A. F. (2000), "In-Place Stiffness and Modulus Measurements," Proceedings of Sessions of ASCE Specialty Conference on Performance Confirmation of Constructed Geotechnical Facilities, Geotechnical Special Publication, No. 94, ASCE, Amherst, MA, pp. 365-376.

Fiedler, S. A., Nelson, C. R., Berkman, E. F. and DiMillio, A. F. (1998), "Soil Stiffness Gauge for Soil Compaction Control," Public Roads, U.S. Department of Transportation, Federal Highway Administration, Vol. 61, No. 4.

Fioravante, V. and Capoferri, R. (2001), “On the Use of Multi-Directional Piezoelectric Transducers in Triaxial Testings," Geotechnical Testing Journal, ASTM, Vol. 24, No. 3, pp. 243-255.

Frost J. D. and Burns, S. E. (2003), "In Situ Subsurface Characterization," The Civil Engineering Handbook, $2^{\text {nd }}$ Edition by W. F. Chen and J. Y. Richard, CRC Press LLC. 
Georgiannou, V. N., Rampello, S., and Silvestri, F. (1991), “Static and Dynamic Measurement of Undrained Stiffness of National Overconsolidated Clays," Proceedings of the $10^{\text {th }}$ European Conference Soil Mechanics, Florence, Vol. 1, pp. 91-96.

Goto, S., Tatsuoka, F., Shibuya, S., and Sato, T. (1991), “A Simple Gauge for Local Strain Measurements in the Laboratory," Soils and Foundations, Vol. 31, No. 1, pp. 169-180.

Greening, P.D. and Nash, D.F.T. (2004). "Frequency domain determination of Go using bender elements" Geotechnical Testing Journal, Vol.27, No.3, 288-294.

Gupta, S., Ranaivoson, A., Edil, T.B., Benson, C.H., and Sawangsuriya, A. (2007), Pavement design using unsaturated soil technology, Report No. MN/RC-2007-11, Minnesota Department of Transportation, MN.

Hardin, B .O. and Black, W. L. (1966), "Sand Stiffness under Various Triaxial Stress," Journal of the Soil Mechanics and Foundations Division, ASCE, Vol. 92, No. SM2, pp. 27-42.

Hardin, B .O. and Richart, F. E., Jr. (1963), "Elastic Wave Velocities in Granular Soils," Journal of the Soil Mechanics and Foundations Division, ASCE, Vol. 89, No. SM1, pp. 33-65.

Hardin, B. O. (1978), "The Nature of Stress-Strain Behavior of Soils," Proceedings of the Geotechnical Engineering Division Specialty Conference on Earthquake Engineering and Soil Dynamics, ASCE, Pasadena, CA, Vol. 1, pp. 1-90.

Hardin, B. O. and Black, W. L. (1968), "Vibration Modulus of Normally Consolidated Clay," Journal of the Soil Mechanics and Foundations Division, ASCE, Vol. 94, No. SM2, pp. 353369.

Hardin, B. O. and Drnevich, V. P. (1972), "Shear Modulus and Damping in Soils: Design Equations and Curves," Journal of the Soil Mechanics and Foundations Division, ASCE, Vol. 98, No. SM7, pp. 667-692.

Hardin, B. O. and Music, J. (1965), “Apparatus for Vibration during the Triaxial Test," Symposium on Instrumentation and Apparatus for Soils and Rocks, ASTM STP 392, pp. 5574.

Hardin, B. O., (1970), "Suggested Methods of Test for Shear Modulus and Damping of Soils by the Resonant Column," ASTM STP 479, Philadelphia, PA, pp. 516-529.

Hill, J. J., Kurdziel, J. M., Nelson, C. R., Nystrom, J. A., and Sondag, M. (1999), “MnDOT Overload Field Tests of Standard and SIDD RCP Installations," Transportation Research Board $78^{\text {th }}$ Annual Meeting, Washington, D.C. (CD-ROM)

Hoar, R. J. and Stokoe, K. H, II (1978), "Generation and Measurement of Shear Waves In Situ," Dynamic Geotechnical Testing, ASTM STP 654, Philadelphia, PA, pp. 3-29.

Hryciw, R. D. and Thomann, T. G. (1993), "Stress-History-Based Model for Ge of Cohesionless Soils," Journal of Geotechnical Engineering, ASCE, Vol. 119, No. 7, pp. 10731093.

Humboldt Mfg. Co. (1999), Humboldt Soil Stiffness Gauge (GeoGauge) User Guide: Version 3.3, Norridge, IL.

Humboldt Mfg. Co. (2000a), Test Results: Evaluation of the Humboldt GeoGauge on Soil-Fly AshCement Mixtures, Norridge, IL.

Humboldt Mfg. Co. (2000b), Test Results: Evaluation of the Humboldt GeoGauge on New Mexico Route 44, Norridge, IL. 
Inci, G., Yesiller, N., and Kagawa, T. (2003), "Experimental Investigation of Dynamic Response of Compacted Clayey Soils," Geotechnical Testing Journal, ASTM, Vol. 26, No. 2, pp. 125-141.

Isenhower, W. M. (1980), “Torsional Simple Shear/Resonant Column Properties of San Francisco Bay Mud," M.S. Thesis, The University of Texas at Austin, Austin, TX.

Isenhower, W. M. and Stokoe, K. H., II (1981), "Strain-Rate Dependent Shear Modulus of San Francisco Bay Mud," Proceedings of the International Conference on Recent Advances in Geotechnical Earthquake Engineering and Soil Dynamic, St. Louis, MO, Vol. 2, pp. 597-602.

Ishibashi, I., and Zhang, X. (1993). "Unified dynamic shear moduli and damping ratios of sand and clay" Soils and Foundations, Vol.33, No.1, 182-191.

Ishihara, K. (1996), Soil Behavior in Earthquake Geotechnics, Oxford University Press, Inc., NY.

Ismail and Rammah (2005). "A new setup for measuring Go during laboratory compaction" Geotechnical Testing Journal, Vol.29, No.4, 1-9.

Ismail, M.A., Sharma, S.S., and Fahey, M. (2005). "A small true triaxial apparatus with wave velocity measurement" Geotechnical Testing Journal, Vol.28, No.2, 1-10.

Iwasaki, T. and Tatsuoka, F. (1977), "Effects of Grain Size and Grading on Dynamic Shear Moduli of Sands," Soils and Foundations, Vol. 17. No. 3, pp. 19-35.

Iwasaki, T., Tatsuoka, F., and Takagi, Y. (1978), "Shear Moduli of Sands under Cyclic Torsional Shear Loading," Soils and Foundations, Vol. 18, No. 1, pp. 39-50.

Jamiolkowski, M., Lancellotta, R., Lo Presti, D. C. F., and Pallera, O. (1994), "Stiffness of Toyoura Sand at Small and Intermediate Strain," Proceedings of the $13^{\text {th }}$ International Conference on Soil Mechanics and Foundation Engineering, New Delhi, pp. 169-172.

Jardine, R. J. (1992), "Some Observations on the Kinetic Nature of Soil Stiffness," Soils and Foundations, Vol. 32, No. 2, pp. 111-124.

Jardine, R. J., Potts, D. M., Fourie, A. B., and Burland, J. B. (1986), "Studies of the Influence of Non-Linear Stress-Strain Characteristics in Soil-Structure Interaction," Geotechnique, Vol. 36, No. 3, pp. 377-396.

Jovicic, V. (1997). The measurement and interpretation on small strain stiffness of soils. Ph.D. thesis, City University.

Jovičić, V. and Coop, M. R. (1998), "The Measurement of Stiffness Anisotropy in Clays with Bender Element Tests in the Triaxial Apparatus," Geotechnical Testing Journal, ASTM, Vol. 21, No. 1, pp. 3-10.

Jovicic, V., Coop, M.R., and Simic, M. (1996). “Objective criteria for determining Gmax from bender elements tests" Geotechnique, Vol.46, No.2, 357-362.

Kawaguchi, T., Mitachi, T., Shibuya, S. (2001). "Evaluation of shear wave travel time in laboratory bender element test" Proceedings of the $15^{\text {th }}$ International Conference on Soil Mechanics and Geotechnical Engineering, Istanbul, Turkey, 155-158.

Kim, D.-S. and Stokoe, K. H., II (1992). “Characterization of resilient modulus of compacted subgrade soils using resonant column and torsional shear tests" Transportation Research Record, No.1369, Washington, D.C., 83-91.

Kokusho, T. (1980), "Cyclic Triaxial Test of Dynamic Soil Properties for Wide Strain Range," Soils and Foundations, Vol. 20, pp. 45-60. 
Kokusho, T. (1987), "In Situ Dynamic Soil Properties and their Evaluation," Proceedings of the $8^{\text {th }}$ Asian Regional Conference on Soil Mechanics and Foundation Engineering, Kyoto, Japan, Vol. 2, pp. 215-435.

Kokusho, T., Yoshida, Y., and Esashi, Y. (1982), “Dynamic Properties of Soft Clays for Wide Strain Range," Soils and Foundations, Vol. 22, No. 4, pp. 1-18.

Kramer, S. L. (1996), Geotechnical Earthquake Engineering, Prentice-Hall, Inc., Upper Saddle River, NJ.

Kuribayashi, E., Iwasaki, T., Tatsuoka, F., and Horiuchi, S. (1975), "Effects of Particle Characteristics on Dynamic Deformational Properties of Soils," Proceedings of the $5^{\text {th }}$ Asian Regional Conference on Soil Mechanics and Foundation Engineering, Bangalore, India, pp. 361-367.

Lade, P. V. and Overton, D. D. (1989), “Cementation Effects in Frictional Materials,” Journal of Geotechnical Engineering, ASCE, Vol. 115, pp. 1373-1387.

Lawrence, F. V., Jr. (1963), "Propagation Velocity of Ultrasonic Wave Through Sand," MIT Research Report R63-8, Massachusetts Institute of Technology, Cambridge, MA.

Lawrence, F.V. (1963). Propagation of ultrasonic waves through sand, Research report R638, MIT, Cambridge.

Lawrence, F.V. (1965). Ultrasonic shear wave velocity in sand and clay, Research report R6505, Soil publication No.17, MIT, Cambridge.

Lee, J.-S. and Santamarina, J. C. (2005). “Bender elements: performance and signal interpretation" Journal of Geotechnical and Geoenvironmental Engineering, ASCE, Vol.131, No.9, 1063-1070.

Lenke, L. R., McKeen, R. G., and Grush, M. (2001), “Evaluation of a Mechanical Stiffness Gauge for Compaction Control of Granular Media," Report NM99MSC-07.2, New Mexico State Highway and Transportation Department, Albuquerque, NM.

Lenke, L. R., McKeen, R. G., and Grush, M. (2003), “Laboratory Evaluation of the GeoGauge for Compaction Control," Transportation Research Record, No. 1849, Washington, D.C., pp. 20-30.

Lewis, M. D. (1990), “A Laboratory Study of the Effect of Stress State on the Elastic Moduli of Sand," Ph.D. Thesis, The University of Texas at Austin, Austin, TX.

Lo Presti, D. C. F., Jamiolkowski, M., Pallara, O., Cavallararo, A., and Pedroni, S. (1997), "Shear Modulus and Damping of Soils," Geotechnique, Vol. 47, No. 3, pp. 603-617.

Lo Presti, D. C. F., Pallara, O., Lancellota, R., Armandi, M., and Maniscalco, R. (1993), "Monotonic and Cyclic Loading Behavior of Two Sands at Small Strains," Geotechnical Testing Journal, ASTM, Vol. 16, No. 4, pp. 409-424.

Lo Presti, D. C. F., Shibuya, S., and Rix, G. J. (2001). "Innovative in soil testing" Pre-failure Deformation Characteristics of Geomaterials. Jamiolkowski, H., Lancellota, R. H., and LoPresti, D. C. F., Eds. Swets and Zeitlinger, Lisse, 1027-1076.

Mair, R. J. (1993), “Developments in Geotechnical Engineering Research: Application to Tunnels and Deep Excavations," Unwin Memorial Lecture 1992, Proceedings of the Institution of Civil Engineers-Civil Engineering, Vol. 97, No. 1, pp. 27-41. 
Mancuso, C., Vassallo, R., and d'Onofrio, A. (2002), “Small Strain Behavior of a Silty Sand in Controlled-Suction Resonant Column-Torsional Shear Tests," Canadian Geotechnical Journal, Vol. 39, No. 1, pp. 22-31.

Matthews, M. C., Clayton, C. R. I., and Own, Y. (2000) "The use of field geophysical techniques to determine geotechnical stiffness parameters" Geotechnical Engineering, Vol.143, 31-42.

Mayne, P. W. (2001), "Stress-Strain-Strength-Flow Parameters from Enhanced In Situ Tests," Proceedings of the International Conference on In Situ Measurement of Soil Properties and Case Histories, Bali, Indonesia, pp. 27-48.

Mayne, P. W., Christopher, B. R., and DeJong, J. (2001), Manual on Subsurface Investigations, National Highway Institute Publication No. FHWA NHI-01-031, FHWA, Washington, D.C.

Mitchell, J. K. and Soga, K. (2005), Fundamentals of Soil Behavior, John Wiley and Sons, Inc., NJ.

Morris, D. V. (1990), “Automatic Feedback System for Resonant Column Testing," Geotechnical Testing Journal, ASTM, Vol. 13, No. 1, pp. 16-23.

Nacci, V. A. and Taylor, K. J. (1967), "Influence of Clay Structure on Elastic Wave Velocities," Proceedings of the International Symposium on Wave Propagation and Dynamic Properties of Earth Materials, Albuquerque, New Mexico, pp. 491-502.

Nakagawa, K., Soga, K., and Mitchell, J. K. (1996), "Pulse Transmission System for Measuring Wave Propagation in Soils," Journal of Geotechnical Engineering, ASCE, Vol. 122, No. 4, pp. 302-308.

Nazarian, S. and Stokoe, K. H., II (1987), "In Situ Determination of Elastic Moduli of Pavements Systems by Special-Analysis-of-Surface-Waves Method (Theoretical Aspects)," Research Report 437-2, Center for Transportation Research, The University of Texas at Austin, Austin, TX.

Nazarian, S., Yuan, D., and Arellano, M. (2002), "Quality Management of Base and Subgrade Materials with Seismic Methods," Transportation Research Record, No. 1786, Washington, D.C., pp. 3-10.

Nazarian, S., Yuan, D., and Baker, M. R. (1994), "Automation of SASW Method," Dynamic Geotechnical Testing II, ASTM STP 1213, Philadelphia, PA, pp. 88-100.

Nazarian, S., Yuan, D., and Tandon, V. (1999), “Structural Field Testing of Flexible Pavement Layers with Seismic Methods for Quality Control," Transportation Research Record, No. 1654, Washington, D.C., pp. 50-60.

Nelson, C. R. and Sondag, M. (1999), "Comparison of the Humboldt GeoGauge with InPlace Quasi-Static Plate Load Tests," CNA Consulting Engineers Report, Minneapolis, MN.

Ni, S. H. (1987), "Dynamic Properties of Sand under True Triaxial Stress States from Resonant Column and Torsion Shear Tests," Ph.D. Thesis, The University of Texas at Austin, TX.

Ohara, S. and Matsuda, H. (1988), "Study on the Settlement of Saturated Clay Layer Induced by Cyclic Shear," Soils and Foundations, Vol. 28, pp. 103-113. 
Pennington, D.S. (1999). The anisotropic small strain stiffness of Cambridge Gault clay. Ph.D. Thesis, University of Bristol.

Ray, R. P. and Woods, R. D. (1988), "Modulus and Damping Due to Uniform and Variable Cyclic Loading," Journal of Geotechnical and Geoenvironmental Engineering, ASCE, Vol. 114, No. 8, pp. 861-876.

Richart, F. E., Hall, J. R., and Woods, R. D. (1970). Vibrations of soils and Foundations. Prentice Hall, Englewood Cliffs.

Richart, F.E. (1977), "Dynamic Stress-Strain Relations for Soils," Proceedings of the $9^{\text {th }}$ International Conference on Soil Mechanics and Foundation Engineering, Tokyo, Vol. 2, pp. 605-612.

Rix, G. J. and Stokoe, K. H., II (1989), "Stiffness Profiling of Pavement Subgrades," Transportation Research Record, No. 1235, Washington, D.C., pp. 1-9.

Robertson, P. K., Campanella, R. G., Gillespie, D., and Rice, A. (1986), “Seismic CPT to Measure In Situ Shear Wave Velocity," Journal of Geotechnical Engineering, ASCE, Vol. 112, No. 8, pp. 71-803.

Roesler, S. K. (1979), "Anisotropic Shear Modulus due to Stress Anisotropy," Journal of the Geotechnical Engineering Division, ASCE, Vol. 105, No. GT7, pp. 871-880.

Saada, A. S. (1988), "Hollow Cylinder Torsional Devices: Their Advantages and Limitation," Advanced Triaxial Testing of Soil and Rock, ASTM STP 977, Philadelphia, PA. pp. 766-779.

Sanchez-Salinero, I., Roesset, J. M., and Stokoe, K. H., II (1986). Analytical studies of body wave propagation and attenuation. Report GR 86-15, University of Texas, Austin, TX.

Sanchez-Salinero, I., Roesset, J. M., Shao, K., Stokoe, K. H., II, and Rix, G. J. (1987), "Analytical Evaluation of Variables Affecting Surface Wave Testing of Pavements," Transportation Research Record 1136, Washington, D.C., pp. 132-144.

Santamarina, J. C., Klein, K. A., and Fam, M. A. (2001), Soils and Waves, John Wiley \& Sons, Chichester, UK.

Sargand, S. M. (2001), “Direct Measurement of Backfill Stiffness for Installation and Design of Buried Pipes," Ohio Research Institute for Transportation and the Environment, Ohio University, $\mathrm{OH}$.

Sargand, S. M., Edwards, W. F., and Salimath, S. (2000), "Evaluation of Soil Stiffness via Non-Destructive Testing," Ohio Research Institute for Transportation and the Environment, Ohio University, $\mathrm{OH}$.

Sawangsuriya, A., Biringen, E., Fratta, D., Bosscher, P. J. and Edil, T. B. (2006). "Dimensionless limits for the collection and interpretation of wave propagation data in soils" GeoShanghai Conference, Site and Geomaterial Characterization, ASCE, Geotechnical Special Publication, No.149, Shanghai, China, 160-166.

Sawangsuriya, A., Bosscher, P. J., and Edil, T. B. (2002), "Laboratory Evaluation of the Soil Stiffness Gauge," Transportation Research Record, No. 1808, Washington, D.C., pp. 30-37.

Sawangsuriya, A., Bosscher, P. J., and Edil, T. B. (2005). Alternative testing techniques for modulus of pavement bases and subgrades. Proceedings of the $13^{\text {th }}$ Annual Great Lakes Geotechnical and Geoenvironmental Engineering Conference, Geotechnical Applications for Transportation Infrastructure, ASCE, Geotechnical Practice Publication, No.3, Milwaukee, WI, 108-121. 
Sawangsuriya, A., Edil, T. B., and Benson, C. H. (2009a). "Effect of suction on resilient modulus of compacted fine-grained subgrade soils" Transportation Research Record 2101, TRB, National Research Council, Washington, D.C., 82-87.

Sawangsuriya, A., Edil, T. B., and Bosscher, P. J. (2003), "Relationship between Soil Stiffness Gauge Modulus and Other Test Moduli for Granular Soils," Transportation Research Record, No. 1849, Washington, D.C., pp. 3-10.

Sawangsuriya, A., Edil, T. B., and Bosscher, P. J. (2004), “Assessing Small-Strain Stiffness of Soils Using the SSG," Proceedings of the $15^{\text {th }}$ Southeast Asia Geotechnical Conference, Bangkok, Thailand, pp. 101-106.

Sawangsuriya, A., Edil, T. B., and Bosscher, P. J. (2008a). "Modulus-suction-moisture relationship for compacted soils" Canadian Geotechnical Journal, Vol.45, No.7, 973-983.

Sawangsuriya, A., Edil, T. B., and Bosscher, P. J. (2009b). "Modulus-suction-moisture relationship for compacted soils in postcompaction state" Journal of Geotechnical and Geoenvironmental Engineering, Vol.135, No.10, 1390-1403.

Sawangsuriya, A., Fall, M., and Fratta, D. (2008b). "Wave-based techniques for evaluating elastic modulus and Poisson's ratio of laboratory compacted lateritic soils" Geotechnical and Geological Engineering, Vol.26, No.5, 567-578.

Sawangsuriya, A., Fratta, D., Bosscher, P. J., and Edil, T. B. (2007a). “S-wave velocity-stress power relationship: packing and contact behavior of sand specimens" Geo-Denver Conference, Advances in Measurement and Modeling of Soil Behavior, ASCE, Geotechnical Special Publication, No.173, Denver, CO, 1-10.

Sawangsuriya, A., Fratta, D., Edil, T. B., and Bosscher, P. J. (2007b). "Small-strain shear modulus anisotropy of compacted soils using bender elements" $60^{\text {th }}$ Canadian Geotechnical Conference $\mathcal{E} 8^{\text {th }}$ Joint CGS/IAH-CNC Groundwater Conference, Ottawa, Canada

Sawangsuriya, A., Sukolrat, J., and Jotisankasa, A. (2008c), "Innovative testing methods for determining stiffness of geomaterials," Seminar of Highway Engineering: Best Practices in Highway Engineering, Department of Highways, Bangkok, Thailand, pp. 589-609.

Saxena, S. K., Avramidis, A. S., and Reddy, K. R. (1988), "Dynamic Moduli and Damping Ratios for Cemented Sands at Low Strains," Canadian Geotechnical Journal, Vol. 25, No. 2, pp. 353-368.

Seed, H. B. and Idriss, I. M. (1970), "Soil Moduli and Damping Factors for Dynamic Response Analyses," Report EERC 70-10, Earthquake Engineering Research Center, University of California, Berkeley, CA.

Sharma, P. V. (1997), Environmental and Engineering Geophysics, Cambridge University Press, Cambridge, UK.

Sheeran, D. E., Baker, W. H., and Krizek, R. J. (1967), "Experimental Study of Pulse Velocities in Compacted Soils," Highway Research Record, No. 177, Washington, D.C., pp. 226-238.

Shibata, T. and Soelarno, D. S. (1975)," Stress-Strain Characteristics of Sands under Cyclic Loading," Proceedings of the Japan Society of Civil Engineering, No. 239, pp. 57-65. (in Japanese) 
Shibuya, S. and Tanaka, H. (1996), "Estimate of Elastic Shear Modulus in Holocene Soil Deposits," Soils and Foundations, Vol. 36, No. 4, pp. 45-55.

Shibuya, S., Hwang, S. C., and Mitachi, T. (1997), “Elastic Shear Modulus of Soft Clays from Shear Wave Velocity Measurement," Geotechnique, Vol. 47, No. 3, pp. 593-601.

Shibuya, S., Mitachi, T., Fukuda, F., and Degoshi, T. (1995), "Strain Rate Effect on Modulus and Damping of Normally Consolidated Clay," Geotechnical Testing Journal, ASTM, Vol. 18, No. 3, pp. 365-375.

Shibuya, S., Tatsuoka, S., Teachavorasinskun, S., Kong, X. J., Abe, F., Kim, Y. S., and Park, C. S. (1992), "Elastic Deformation Properties of Geomaterials," Soils and Foundations, Vol. 32, No. 3, pp. 26-46.

Shirley, D.J. (1978). "An improved shear wave transducer" J. Acoust. Soc. Am., 63, No.5, 1643-1645.

Shirley, D.J. and Hampton, L.D. (1978). "Shear-wave measurements in laboratory sediments" J. Acoust. Soc. Am., Vol.63, No.2, 607-613.

Silver, M. L. and Seed, H. B. (1971), "Deformation Characteristics of Sands under Cyclic Loading," Journal of the Soil Mechanics and Foundations Division, ASCE, Vol. 97, No. SM8, pp. 1081-1098.

Silvestri, F. (1991), "Stress-Strain Behaviour of Natural Soils by Means of Cyclic/Dynamic Torsional Shear Tests," Experimental Characterization and Modelling of Soils and Soft Rocks, The University of Napoli Federico, pp. 7-73.

Souto, A., Hartikainen, J., and Özüdoğru, K. (1994), "Measurement of Dynamic Parameters of Road Pavement Materials by the Bender Element and Resonant Column Tests," Geotechnique, Vol. 44, No. 3, pp. 519-526.

Stokoe, K. H., II and Richart, F. E., Jr. (1973), "In Situ and Laboratory Shear Wave Velocities," Proceedings of the $8^{\text {th }}$ International Conference on Soil Mechanics and Foundation Engineering, Vol. 1, Part 2, Moscow, U.S.S.R., pp. 403-409.

Stokoe, K. H., II and Woods, R. D. (1972), "In Situ Shear Wave Velocity by Cross-Hole Method," Journal of the Soil Mechanics and Foundations Division, ASCE, Vol. 98, No. SM5, pp. 443-460.

Stokoe, K. H., II, Hwang, S. K., Lee, J. N.-K., and Andrus, R. D. (1995), “Effects of Various Parameters on the Stiffness and Damping of Soils at Small to Medium Strains," Prefailure Deformation of Geomaterials, Balkema, Rotterdam, Vol. 2, pp. 785-816.

Stokoe, K. H., II, Lee, S. H. H., and Knox, D. P. (1985), "Shear Moduli Measurement under True Triaxial Stresses," Proceedings of the Geotechnical Engineering Division: Advances in the Art of Testing Soil Under Cyclic Conditions, ASCE, Detroit, MI, pp. 166-185.

Sukolrat, J. (2007). Destructuration of Bothkennar clay, Ph.D. Thesis, Department of Civil Engineering, University of Bristol, UK.

Tatsuoka, F. and Shibuya, S. (1991), "Deformation Characteristics of Soils and Rocks from Field and Laboratory Tests," Proceedings of the $9^{\text {th }}$ Asian Regional Conference on Soil Mechanics and Foundation Engineering, Bangkok, Thailand, Vol. 2, pp. 101-170.

Thomann, T. G. and Hryciw, R. D. (1990), "Laboratory Measurement of Small Strain Shear Modulus under Ko Conditions," Geotechnical Testing Journal, ASTM, Vol. 13, No. 2, pp. 97-105. 
Trudeau, P. J., Whitman, R. V., and Christian, J. T. (1974), "Shear Wave Velocity and Modulus of a Marine Clay," Journal of the Boston Society of Civil Engineers, Vol. 61, No. 1, pp. 12-25.

Viggiani, G. (1992). Small strain stiffness of fine grained soils. Ph.D. Thesis, City University.

Viggiani, G. and Atkinson, J. H. (1995a), "Stiffness of Fine-Grained Soil at Very Small Strains," Geotechnique, Vol. 45, No. 2, pp. 249-265.

Viggiani, G. and Atkinson, J. H. (1995b), "Interpretation of Bender Element Tests," Geotechnique, Vol. 45, No. 1, pp. 149-154.

Viggiani, G. and Atkinson, J. H. (1997), Discussion: "Interpretation of Bender Element Tests," Geotechnique, Vol. 47, No. 4, pp. 873-877.

Vucetic, M. and Dobry, R. (1991), "Effect of Soil Plasticity on Cyclic Response," Journal of Geotechnical Engineering, ASCE, Vol. 117, No. 1, pp. 89-107.

Weaver, E., Ormsby, W. C., and Zhao, X. (2001), Pavement Variability Study: Phase I Interim Report, National Pooled Fund Study 2(212), Non-Nuclear Testing of Soils and Granular Bases Using the GeoGauge (Soil Stiffness Gauge) and Other Similar Devices, U.S. Department of Transportation, Federal Highway Administration.

Wilson, S. D. and Dietrich, R. J. (1960), "Effect of Consolidation Pressure on Elastic and Strength Properties of Clay," Proceedings of the Soil Mechanics and Foundations Division, Research Conference on Shear Strength of Cohesive Soils, ASCE, Boulder, CO, pp. 419-435.

Woods, R. D. (1978), "Measurement of Dynamic Soil Properties," Proceedings of the Earthquake Engineering and Soil Dynamics Specialty Conference, ASCE, Pasadena, CA, Vol. 1, pp. 91-178.

Wright, S. G., Stokoe, K. E., II, and Roesset, J. M. (1994), "SASW Measurements at Geotechnical Sites Overlaid by Water," Dynamic Geotechnical Testing II, ASTM STP 1213, Philadelphia, PA, pp. 39-57.

Wu, W., Arellano, M., Chen, D.-H., Bilyeu, J., and He., R. (1998), “Using a Stiffness Gauge as an Alternative Quality Control Device in Pavement Construction," Texas Department of Transportation Report, Austin, TX.

Yesiller, N., Inci, G., and Miller, C. J. (2000), “Ultrasonic Testing for Compacted Clayey Soils," Proceedings of Sessions of Geo-Denver 2000, Advances in Unsaturated Geotechnics, ASCE, Geotechnical Special Publication, No. 99, Denver, CO, pp. 54-68.

Yu, P. and Richart, F. E., Jr. (1984), "Stress Ratio Effects on Shear Modulus of Dry Sands," Journal of the Geotechnical Engineering Division, ASCE, Vol. 110, No. GT3, pp. 331-345.

Yun, T. S. and Santamarina, J. C. (2005), “Decementation, Softening, and Collapse: Changes in Small-Strain Shear Stiffness in Ko Loading," Journal of Geotechnical and Geoenvironmental Engineering Division, ASCE, Vol. 131, No. 3, pp. 350-358.

Zen, K., Umehara, Y., and Hamada, K. (1978), "Laboratory Tests and In Situ Seismic Survey on Vibratory Shear Modulus of Clayey Soils with Various Plasticities," Proceedings of the $5^{\text {th }}$ Japanese Earthquake Engineering Symposium, pp. 721-728.

Zeng, X. and Ni, B. (1998), “Application of Bender Elements in Measuring Gmax of Sand under Ko Condition," Geotechnical Testing Journal, ASTM, Vol. 21, No. 3, pp. 251-263.

Zeng, X., Figueroa, J. L., and Fu, L. (2002). Measurement of base and subgrade layer stiffness using bender element technique. Proc. of the $15^{\text {th }}$ ASCE Engineering Mechanics Conference, Columbia University, New York, NY, 1-10. 